\title{
A glycine zipper motif mediates the formation of toxic $\beta$-amyloid oligomers in vitro and in vivo
}

\author{
Virginia Fonte ${ }^{1}$, Vishantie Dostal ${ }^{1}$, Christine M Roberts ${ }^{1}$, Patrick Gonzales ${ }^{1}$, Pascale Lacor ${ }^{2}$, Jordi Magrane ${ }^{3}$, \\ Natalie Dingwell ${ }^{4}$, Emily Y Fan ${ }^{4}$, Michael A Silverman ${ }^{4}$, Gretchen H Stein ${ }^{5}$ and Christopher D Link ${ }^{1,6^{*}}$
}

\begin{abstract}
Background: The $\beta$-amyloid peptide $(A \beta)$ contains a Gly-XXX-Gly-XXX-Gly motif in its C-terminal region that has been proposed to form a "glycine zipper" that drives the formation of toxic $A \beta$ oligomers. We have tested this hypothesis by examining the toxicity of $A \beta$ variants containing substitutions in this motif using a neuronal cell line, primary neurons, and a transgenic C. elegans model.

Results: We found that a Gly37Leu substitution dramatically reduced A $\beta$ toxicity in all models tested, as measured by cell dysfunction, cell death, synaptic alteration, or tau phosphorylation. We also demonstrated in multiple models that $A \beta$ Gly37Leu is actually anti-toxic, thereby supporting the hypothesis that interference with glycine zipper formation blocks assembly of toxic $A \beta$ oligomers. To test this model rigorously, we engineered second site substitutions in $A \beta$ predicted by the glycine zipper model to compensate for the Gly37Leu substitution and expressed these in C. elegans. We show that these second site substitutions restore in vivo Aßtoxicity, further supporting the glycine zipper model.

Conclusions: Our structure/function studies support the view that the glycine zipper motif present in the Cterminal portion of $A \beta$ plays an important role in the formation of toxic $A \beta$ oligomers. Compounds designed to interfere specifically with formation of the glycine zipper could have therapeutic potential.
\end{abstract}

Keywords: Alzheimer's disease, C. elegans, pore-forming toxin, glycine motif

\section{Background}

Many studies support the view that accumulation of the $\beta$-amyloid peptide $(A \beta)$ is central to Alzheimer's disease pathology [1]. Synthetic A $\beta$ is toxic in both neuronal cell lines [2,3] and primary neurons [4], and Alzheimer's-like pathology has been observed in a range of transgenic models that accumulate $A \beta$ [5-8]. Although numerous studies have implicated oligomeric $A \beta$ as the toxic species [9-11], the structure of the key toxic $A \beta$ species is unresolved, as is the toxic mechanism. As it has not been possible to obtain atomic structures for $A \beta$ by $\mathrm{X}$-ray crystallography, there is significant disagreement as to whether the toxic form of $A \beta$ involves an $\alpha$ helical or $\beta$-sheet structure.

\footnotetext{
* Correspondence: linkc@colorado.edu

${ }^{1}$ Institute for Behavioral Genetics, University of Colorado, Boulder, CO 80309, USA

Full list of author information is available at the end of the article
}

Synthetic A $\beta$ preparations can convincingly form pores in synthetic membranes, leading to the proposal that in vivo $\mathrm{A} \beta$ toxicity results specifically from direct membrane damage [12]. Interestingly, the hydrophobic $\mathrm{C}$-terminal region of $\mathrm{A} \beta$ (corresponding to the transmembrane portion of the amyloid precursor protein, APP) contains a Gly-XXX-Gly-XXX-Gly motif, termed a "glycine zipper" by Kim et al [13]. These researchers pointed out that this motif is present in the transmembrane domains of a number of bacterial channel proteins, and structural modeling of these channel proteins suggests that the glycine zipper motif can drive the packing of transmembrane $\alpha$-helices. A schematic model showing the potential glycine zipper motif interface between $\alpha$-helical regions of two $A \beta$ peptides is shown in Figure 1. To support the idea that the glycine zipper motif of $A \beta$ drives the formation of membrane pores, Kim et al demonstrated that Gly-to-Leu substitutions in this motif (particularly the G37L substitution)
C Biomed Central

C 2011 Fonte et al; licensee BioMed Central Ltd. This is an Open Access article distributed under the terms of the Creative Commons Attribution License (http://creativecommons.org/licenses/by/2.0), which permits unrestricted use, distribution, and reproduction in any medium, provided the original work is properly cited. 


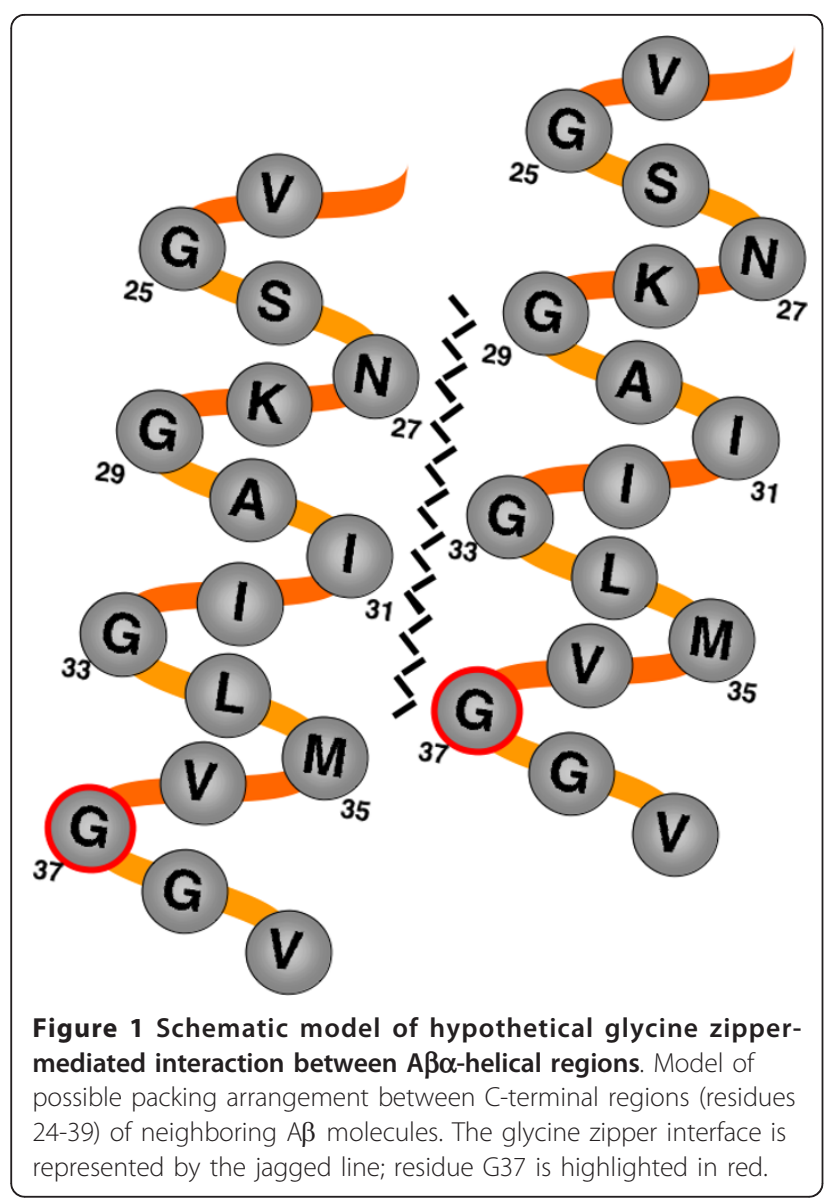

could block $A \beta$ pore formation in synthetic membranes and reduce $A \beta$ toxicity in cultured Neuro 2a neuroblastoma cells. However, these studies did not directly demonstrate that the G37L substitution disrupted the formation of $A \beta$ oligomers, or that oligomer disruption was the basis for the reduced toxicity in cell culture.

Hung et al [14] compared the toxicity of synthetic $A \beta$ 1-42 containing G25L, G29L, G33L or G37L substitutions (generally termed GSL peptides) to wild type $A \beta$ in primary mouse cortical neurons. These substitutions were all found to be less toxic than wild type $A \beta$, with the G33L and G37L substitutions having the greatest reduction in toxicity. The reduced toxicity of these GSL peptides was correlated with reduced formation of smaller $\mathrm{A} \beta$ oligomers (dimers, trimers, tetramers, and pentamers) in vitro. These researchers also found that the GSL peptides had increased rates of fibril formation using an in vitro Thioflavin $\mathrm{T}$ assay. Harmeier et al [15] examined the role of G29 and G33 in A $\beta$ 1-42 toxicity and oligomerization, and found that substitutions at G33 (G33A or G33I) dramatically reduced A $\beta$ toxicity in neuroblastoma cells and biased in vitro oligomerization towards higher molecular weight forms. These researchers also demonstrated that unlike wild type $A \beta$,
G33-substituted A $\beta$ did not inhibit hippocampal LTP or disrupt eye formation in a Drosophila transgenic $A \beta$ expression model.

In theory, the relevance of the glycine zipper to $A \beta$ toxicity could be explored in transgenic mouse models expressing Amyloid Precursor Protein (APP) that contains substitutions in the glycine zipper motif. However, this motif has been demonstrated to play a role in the dimerization of APP, and substitutions in the motif alter APP proteolytic processing and $\mathrm{A} \beta$ production $[16,17]$, thus confounding any interpretations of this hypothetical model. We have therefore employed a transgenic $C$. elegans model [18] that directly expresses $\mathrm{A} \beta 42$ to assay effects of glycine zipper substitutions, particularly G37L, on toxicity and amyloid formation, neither of which has been previously tested in vivo. To address the important issue of whether the correlations between the effects of glycine zipper substitutions on oligomerization and toxicity are causally linked, we used multiple cell models to ask whether G37L substitutions are actually anti-toxic, a prediction of the toxic oligomer model. Finally, we used second site substitutions in $\mathrm{A} \beta$ G37L to test rigorously structural predictions of the glycine zipper model in vivo.

\section{Results}

\section{$A \beta 42 \mathrm{G} 37 \mathrm{~L}$ is less toxic than wild type $A \beta$ in vivo}

We have previously described and characterized a transgenic C. elegans model in which induction of human A $\beta 42$ expression leads to intracellular accumulation of $A \beta$ in body wall muscle cells, resulting in a highly reproducible paralysis phenotype $[5,18]$. To determine if a G37L substitution in $A \beta$ would alter toxicity in this model, we generated transgenic strains (chromosomallyintegrated transgenic arrays) with inducible muscle-specific expression of $A \beta$ G37L, using either a dominant morphological marker [pRF4, rol-6(su1006), dominant Roller phenotype] or GFP expression [pCL26, Pmtl-2:: GFP, constitutive intestinal GFP] as co-transformation markers. We compared the paralysis kinetics of two independent strains [CL3523 (Pmyo-3::A $\beta$ G37L minigene + pRF4) and CL2621 (Pmyo-3::A $\beta$ G37L minigene + pCL26)] to paired control transgenic strains expressing equivalent levels of wild type A $\beta$ (CL4176 and CL2659, respectively). (See Additional file 1 Table S1 for all transgenic $C$. elegans strains used in this study.) As shown in Figure 2 (panels $A$ and $B$ ), both $A \beta$ G37L strains had dramatically reduced rates of paralysis in comparison to the control strains. Despite the reduced paralysis rates, these strains had similar levels of $A \beta$ expression (Figure 2C), and the distribution of immunoreactive intracellular $A \beta$ deposits was not changed in the $A \beta$ G37L strains (Figure 2D). We did note a variable pattern of immunoreactive bands between strains 


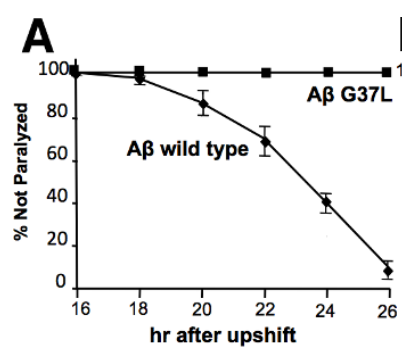

B

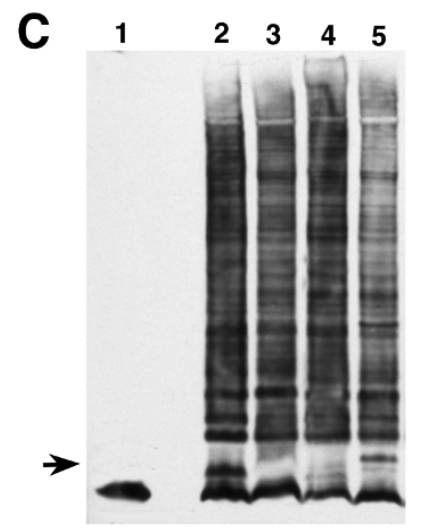

D

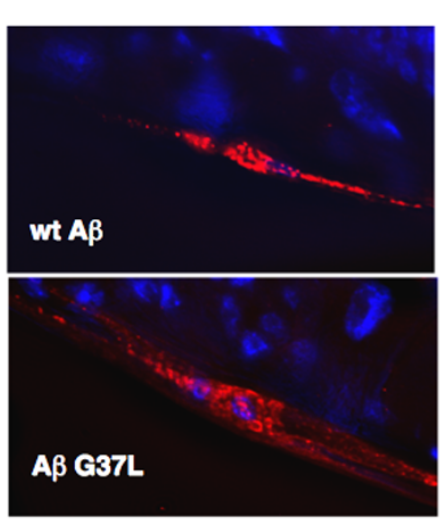

E

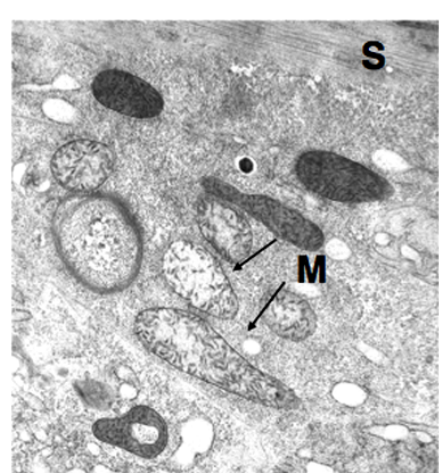

A $\beta$ wild type

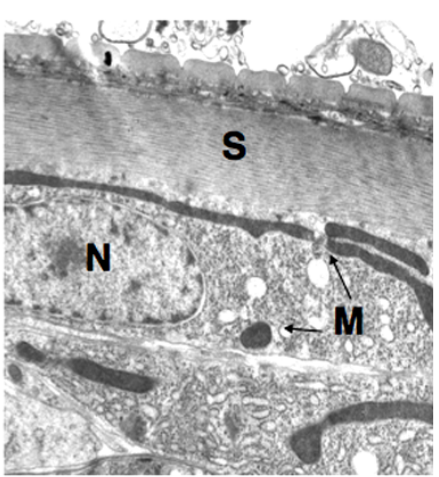

A $\beta$ G37L

Figure 2 Reduced toxicity of $\mathbf{A} \boldsymbol{\beta}$ G37L expressed in C. elegans. A. Representative plot of paralysis onset in transgenic worms induced to express $A \beta$ wild type (strain CL4176) or A $\beta$ G37L (strain CL3523). In both of these strains the transgenes are marked with the dominant Roller mutation rol-6(su 1006). B. Paralysis plot for an independent pair of transgenic strains induced to express A $\beta$ wild type (CL2659) or A $\beta$ G37L (CL2621). In both of these strains the transgenes are marked with the intestinal GFP marker Pmtl-2::GFP. C. Representative immunoblot of worm protein extracts (20 $\mathrm{mg} / \mathrm{lane})$ probed with anti-A $\beta$ monoclonal antibody 6E10. Lane 1, $25 \mathrm{ng}$ synthetic A 1 1-42; lane 2, CL4176 (A $\beta$ wild type); lane 3, CL2659 (A $\beta$ wild type); lane 4, CL3523 (A $\beta$ G37L); lane 5, CL2621 (A $\mathrm{G}$ G37L). Note that although the overall patterns of oligomeric $A \beta$ bands were similar in strains expressing $A \beta$ wild type or $A \beta G 37 \mathrm{~L}$, differences did appear in the region of dimeric $A \beta$ (arrow). D. Immunostaining with mAb 6E10 of transgenic worms expressing A $\beta$ wild type (upper panel) or A $\beta$ G37L (lower panel). Nuclei stained with DAPI (blue), $6 \mathrm{E} 10$ immunoreactivity in red. Size bar $=10 \mu \mathrm{m}$. E. Electron micrographs of sections of transgenic worms fixed by high pressure freezing. Left panel, section through body wall muscle of worm expressing A $\beta$ wild type (CL4176). Note abnormal "light" mitochondria (arrows). Right panel, equivalent section through body wall of transgenic worm expressing A $\beta$ G37L (CL3523). Note normal dark mitochondria (arrows). $S=$ sarcomeres, $\mathrm{N}=$ nucleus, $\mathrm{M}=$ mitochondria. Size bar $=1 \mu \mathrm{m}$.

(arrow, Figure 2C), but this did not consistently correlate with genotypes or phenotypes. In addition, a significant ultrastructural difference was observed between muscle cells expressing wild type and G37L variant $A \beta$ : abnormal mitochondria with reduced electron density ("light" mitochondria) were observed in the large majority (> 85\%) of body wall muscle cells expressing wild type $A \beta$ while these were exceedingly rare in worms expressing A $\beta$ G37L (Figure 2E, 1/71 muscles scored, 9 worms sectioned).

The reduced toxicity of $A \beta G 37 \mathrm{~L}$ in the transgenic $C$. elegans model could theoretically be due to the 
introduction of a leucine residue rather than removal of G37. We therefore constructed a transgenic line expressing $A \beta$ G37F, and found that this substitution also dramatically reduced $A \beta$ toxicity in the $C$. elegans model (Figure 3). An alternative interpretation for the reduced toxicity of the G37L substitution is that the glycine-toleucine substitution simply increases the hydrophobicity of $A \beta$. However, we observed that a transgenic strain expressing the $A \beta$ triple glycine zipper substitution (G29L G33L G37L) was actually slightly more toxic than A $\beta$ G37L. While the model of Kim et al [13] predicts that the reduced toxicity of glycine zipper substitutions results from an interruption of $\alpha$-helix packing, these substitutions could also conceivably interfere with $\beta$-sheet formation. We have previously demonstrated that a leucine-to-proline substitution at $A \beta$ position 17 (L17P), which is strongly predicted to interfere with $\beta$ sheet formation by the central hydrophobic core of $A \beta$, blocks in vivo amyloid formation [19]. We therefore compared the toxicity of induced $A \beta$ L17P to $A \beta$ wild type and $A \beta$ G37L, and observed that the toxicity of the L17P variant was comparable to that of wild type $A \beta$ Figure 3. While this result does not rule out the possibility that the G37L substitution disrupts $\beta$-sheet formation, it does show that interfering with the ability of $A \beta$ to form $\beta$-sheet structure does not by itself reduce $A \beta$ toxicity in this model.

We have previously shown that the $A \beta$ sequence can act as a modular aggregation domain, such that the $\mathrm{C}$ terminal addition of $A \beta 3-42$ to GFP converts this normally soluble protein to a strongly aggregating one [20]. Introduction of an L17P substitution into the $A \beta$ sequence reverses this aggregation capacity, thus GFP:: A $\beta$ L17P is soluble when expressed in C. elegans or hippocampal neurons. To test if the G37L substitution reduced $A \beta$ toxicity by similarly blocking $A \beta$ aggregation, we examined the distribution of GFP::A $\beta$ G37L expressed in C. elegans muscle. As shown in Figure 4A, GFP::A $\beta$ G37L readily formed inclusions in C. elegans, demonstrating that the G37L substitution does not interfere with $\mathrm{A} \beta$-driven aggregation in vivo.

Constitutive expression of wild type $\mathrm{A} \beta$ in $C$. elegans body wall muscle leads to the formation of intracellular amyloid deposits detectable with amyloid dyes Thioflavin $S[5,19]$ or $\mathrm{X}-34$ [21]. We generated worms with constitutive A $\beta$ G37L expression in muscle (Punc-54::A $\beta$ G37L minigene) and found that this $A \beta$ variant did not make detectable amyloid (Figure 4B, C). Thus, while the G37L substitution did not block general A $\beta$ aggregation, it did prevent amyloid formation in this in vivo model.

\section{Synthetic $A \beta$ G37L is anti-toxic in Neuro 2a cells}

To investigate whether $A \beta$ G37L is anti-toxic, we first turned to a transformed cell culture model where $A \beta$ exposure could be carefully controlled. Kim et al (13) reported that synthetic A $\beta$ G37L was significantly less toxic to Neuro 2a cells than synthetic wild type $A \beta$. To determine if the presence of $A \beta$ G37L could inhibit the toxicity of wild type $A \beta$ to Neuro 2 a cells, increasing amounts of $A \beta 1-42$ G37L were added to wild type $A \beta$ 1-42 immediately after solubilization of these peptides. (Before solubilization, the peptides were rendered monomeric by pre-treatment with HFIP and subsequent desiccation.) As shown in Figure 5A, progressive addition of $A \beta$ G37L led to a progressive reduction of wild type $A \beta$ toxicity, such that at equal concentrations of wild type and G37L $A \beta$, loss of cell viability was equivalent to that of the vehicle control. These results could be due to a direct interaction between the wild type and variant peptide (e.g., A $\beta$ G37L inhibiting the formation of a toxic oligomer by wild type $A \beta$ ), or an indirect effect (e.g., competition between the peptides for some toxic target). To distinguish between these possibilities, we compared the toxicity of equimolar mixtures

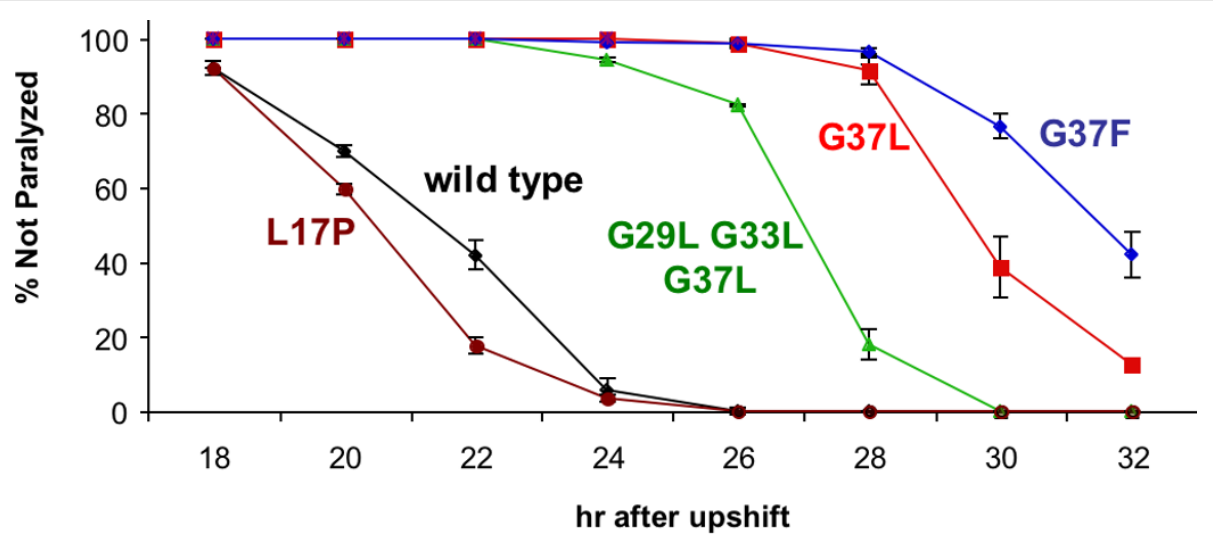

Figure 3 Relative paralysis rates of worms expressing wild type or variant $\mathbf{A} \boldsymbol{\beta}$. Representative plot of transgenic worms induced to express

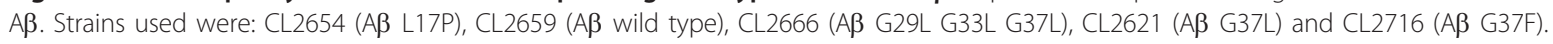


A
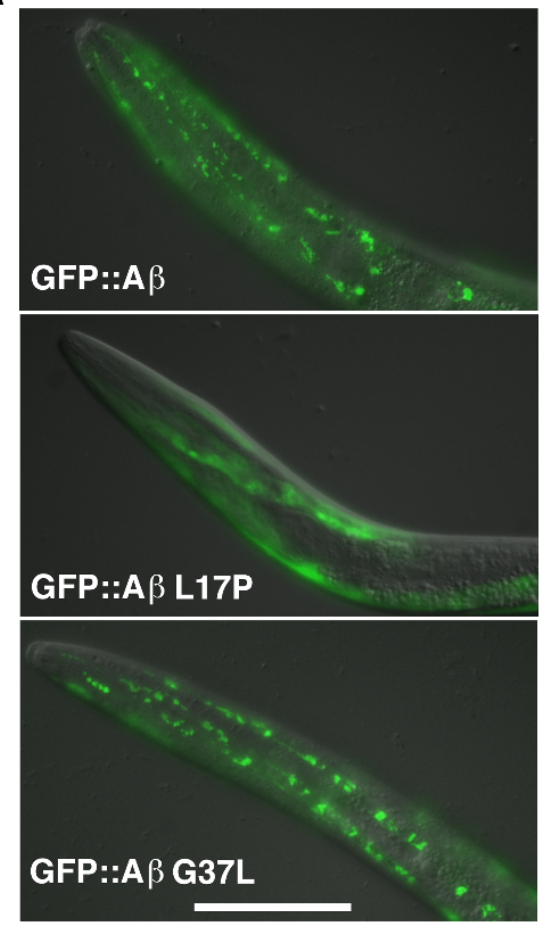

B
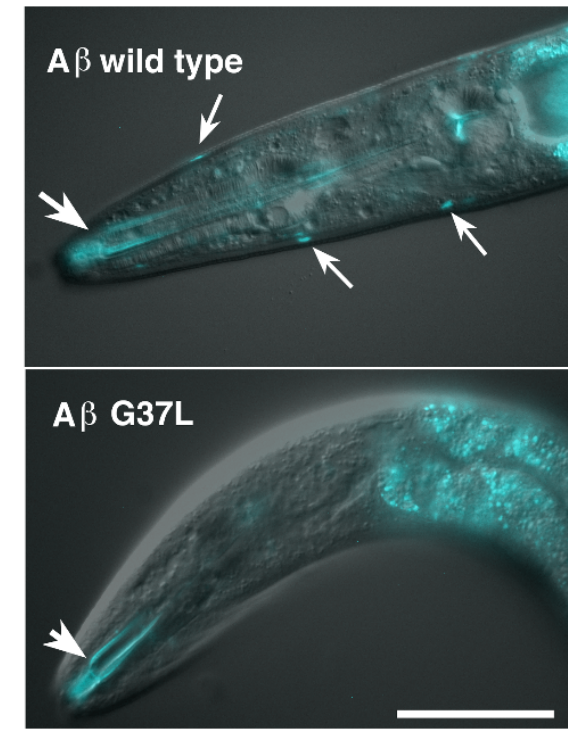

C

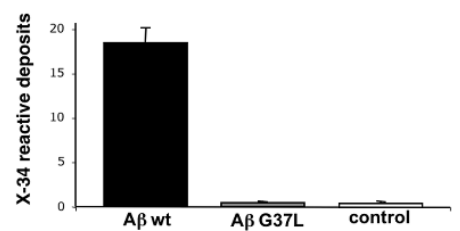

Figure 4 Effect of G37L substitution on $\mathbf{A} \boldsymbol{\beta}$ mediated aggregation and $\boldsymbol{\beta}$-amyloid formation. A. Digital overlay of differential interference contrast (DIC) and epifluorescence images of live transgenic worms expressing GFP::A $\beta$ fusion proteins. Top panel, third larval stage worm expressing GFP::Aßwild type fusion protein (strain CL1332). Note GFP inclusions in body wall muscle. Middle panel, third larval stage worm expressing GFP::A $\beta$ L17P fusion protein (strain CL1364). Note diffuse GFP in body wall muscle. Lower panel, third larval stage worm expressing GFP::ABG37L fusion protein. Note similar GFP inclusions as observed in worms expressing GFP::A $\beta$ wild type (top panel). Size bar $=100 \mu \mathrm{m}$. B Amyloid formation in transgenic worms with constitutive muscle expression of A $\beta$ wild type or G37L. DIC/epifluorescence images of live adult transgenic worms stained with amyloid-specific dye X-34 (33). Top panel, CL2006 (wild type Aßexpression). Note lateral amyloid deposits (small arrows) in body wall muscle and non-specific staining of the buccal cavity (large arrow). Lower panel, CL2564 (AßG37L). Muscle X-34 deposits are undetectable, although staining is still seen in the buccal cavity (large arrow). Size bar $=100 \mu \mathrm{m}$. C. Quantification of X-34 deposits in CL2006 (Aßwild type), CL2564 (AßG37L), and CL802 (control non-transgenic) worms. Error bars = S.E.M.

prepared as described above to mixtures in which the individual peptides were solubilized and allowed to oligomerize separately for 20 min before addition to the Neuro 2a cells. As shown in Figure 5B, individual incubation of the peptides prevented $A \beta$ G37L from interfering with wild type $A \beta$ toxicity $(P<0.05$, Student's $T$ test), consistent with the model that the $A \beta G 37 \mathrm{~L}$ variant can directly interfere with the formation of toxic oligomers by wild type $\mathrm{A} \beta$.

\section{Synthetic $A \beta$ G37L is anti-toxic in mammalian hippocampal neurons}

In the experiment described above, we did not biochemically characterize the oligomerization of the $A \beta$ peptides, and interpretation of the toxicity assay was limited by the use of immortal cultured cells. A $\beta$ oligomers have been shown to be highly toxic when added to primary hippocampal neurons [22], so we attempted to replicate the Neuro 2a findings in a more disease-relevant primary neuronal culture system. We first examined the ability of synthetic A $\beta$ 1-42 G37L to form oligomers in vitro, using two oligomerization protocols: the globulomer protocol of Barghorn et al [23] and the ADDL (A $\beta$ Derived Diffusible Ligand) protocol of Lambert et al [24]. As shown in Figure $6 \mathrm{~A}$, synthetic $A \beta$ G37L readily formed oligomers in vitro, and formed higher molecular weight species than wild type $A \beta$ 1-42, as has been previously reported for glycine-substituted $\mathrm{A} \beta$ peptides $(14,15)$. The toxicity of G37L ADDLs was assayed using primary hippocampal neurons as previously described $[25,26]$. Drebrin expression was used as a specific read-out of $A \beta$ toxicity, as this is a critical dendritic spine protein, and synapses are key targets of ADDL toxicity [25]. Exposure of hippocampal neurons to ADDLs (500 $\mathrm{nM}$ ) formed from wild type $\mathrm{A} \beta$ caused a significant reduction in drebrin detected by 


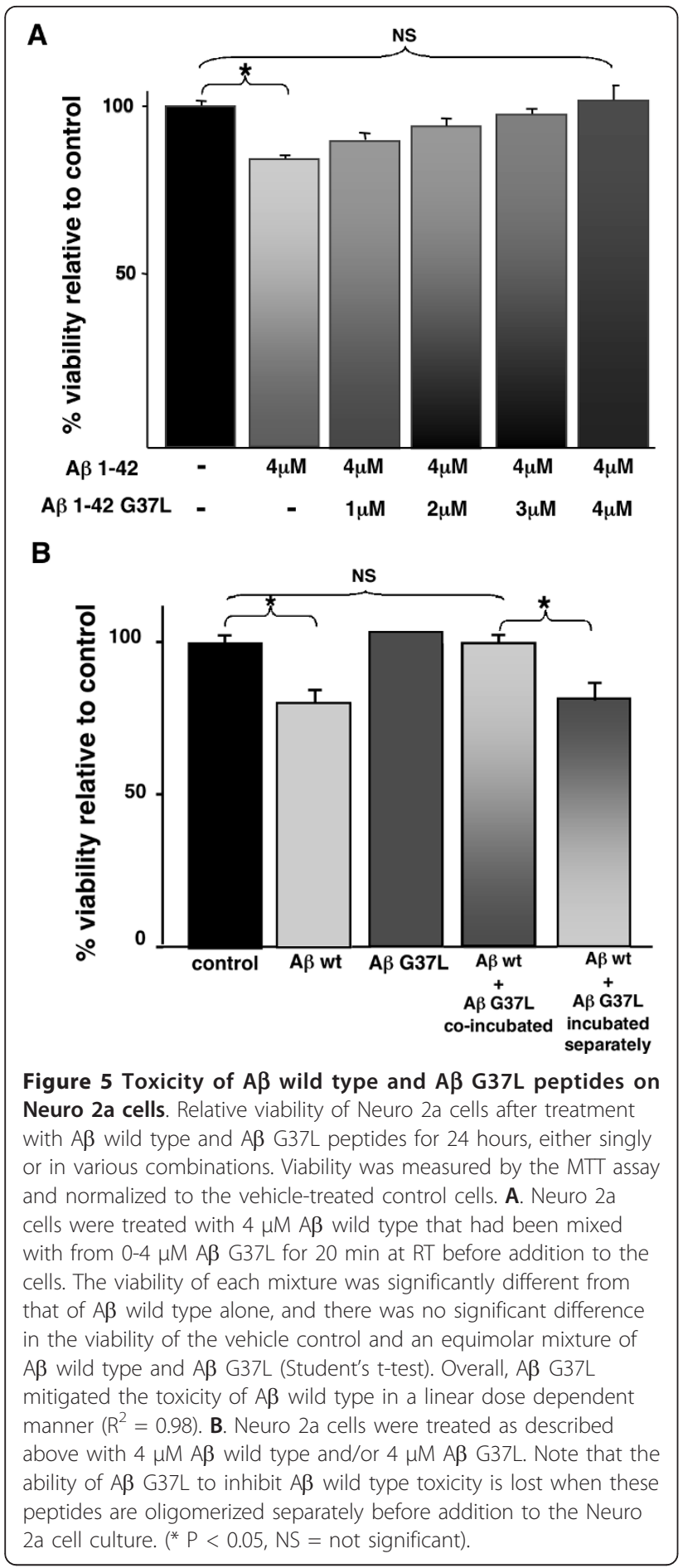

immunocytochemistry compared to vehicle-treated cells. A comparable reduction was not observed when neurons were exposed to ADDLs derived from $A \beta$ G37L (Figure $6 \mathrm{~B}, \mathrm{C}, \mathrm{D}$ ). The reduced toxicity of G37L ADDLs did not result from the inability of these oligomers to bind to hippocampal neurons, as immunostaining with an oligomer-specific antibody (NU1) revealed a robust association of these ADDLs with neurons (Figure $6 \mathrm{E})$. The $\mathrm{A} \beta$ G37L peptide was also anti-toxic in this model, as mixing together wild type and G37L peptides resulted in non-toxic ADDLs (Figure 6F). However, unlike the situation in Neuro 2a cells, the A $\beta$ G37L was anti-toxic even when pre-incubated with primary neurons before addition of wild type A $\beta$ ADDLs (Additional File 1 Figure S1).

Deposition of hyper-phosphorylated tau is an important component of Alzheimer's pathology, and $A \beta$ ADDL oligomers have been shown to induce tau hyperphosphorylation in hippocampal neurons in culture [27]. We therefore also compared the abilities of wild type and G37L ADDLs to induce tau phosphorylation. We treated primary hippocampal neuronal cultures with ADDLs composed of wild type, G37L, or sequencescrambled $A \beta$ 1-42, and phospho-tau levels were quantified by immunofluorescence imaging after staining with PHF-1, an antibody that recognizes AD-related tau phosphorylation at residues Ser396 and Ser404. Vehicletreated controls demonstrated low levels of phospho-tau (Figure 7A), similar to those observed in untreated neurons, whereas neurons treated with $0.5 \mathrm{mM}$ wild type ADDLs had higher phospho-tau levels after 18 hours (Figure 7D). No difference was observed in neurons treated with either $0.5 \mathrm{mM}$ scrambled ADDLs or G37L ADDLs (Figures 7B and 7C) at 18 hours compared to vehicle. Statistical analysis of quantitative immunofluorescence data revealed a twofold $(\mathrm{P}<0.01)$ increase in tau phosphorylation in neurons treated with the wild type at 4 hours compared to vehicle, and a fourfold ( $\mathrm{P}<$ 0.01 ) increase in tau phosphorylation at $18 \mathrm{hr}$ (Figure 7E). Neither G37L nor scrambled ADDLs showed phospho-tau levels significantly different from vehicle-only treated neurons at either time (Figure 7E).

\section{Adenovirus-transfected $A \beta$ G37L is anti-toxic in primary cortical neurons}

In the C. elegans model, cells were exposed to $A \beta$ produced endogenously from an inducible transgene, rather than added exogenously as in the experiments described above. To replicate this pattern of $A \beta$ expression in mammalian neurons, we turned to an inducible adenovirus transfection system $[28,29]$. This system employs engineered adenovirus that contain a signal peptide:: $A \beta$ 1-42 minigene (directly analogous to the $A \beta$ minigene used in the worm model) under control of a doxycycline-inducible promoter. In this model, doxycycline induction after transfection of rat primary cortical neurons with a viral vector expressing wild type $A \beta$ 1-42 leads to a significant increase in toxicity (measured by appearance of apoptotic neurons or reduced synaptophysin staining) compared to uninduced transfected neurons. As shown in Figure 8A, we found that neurons 

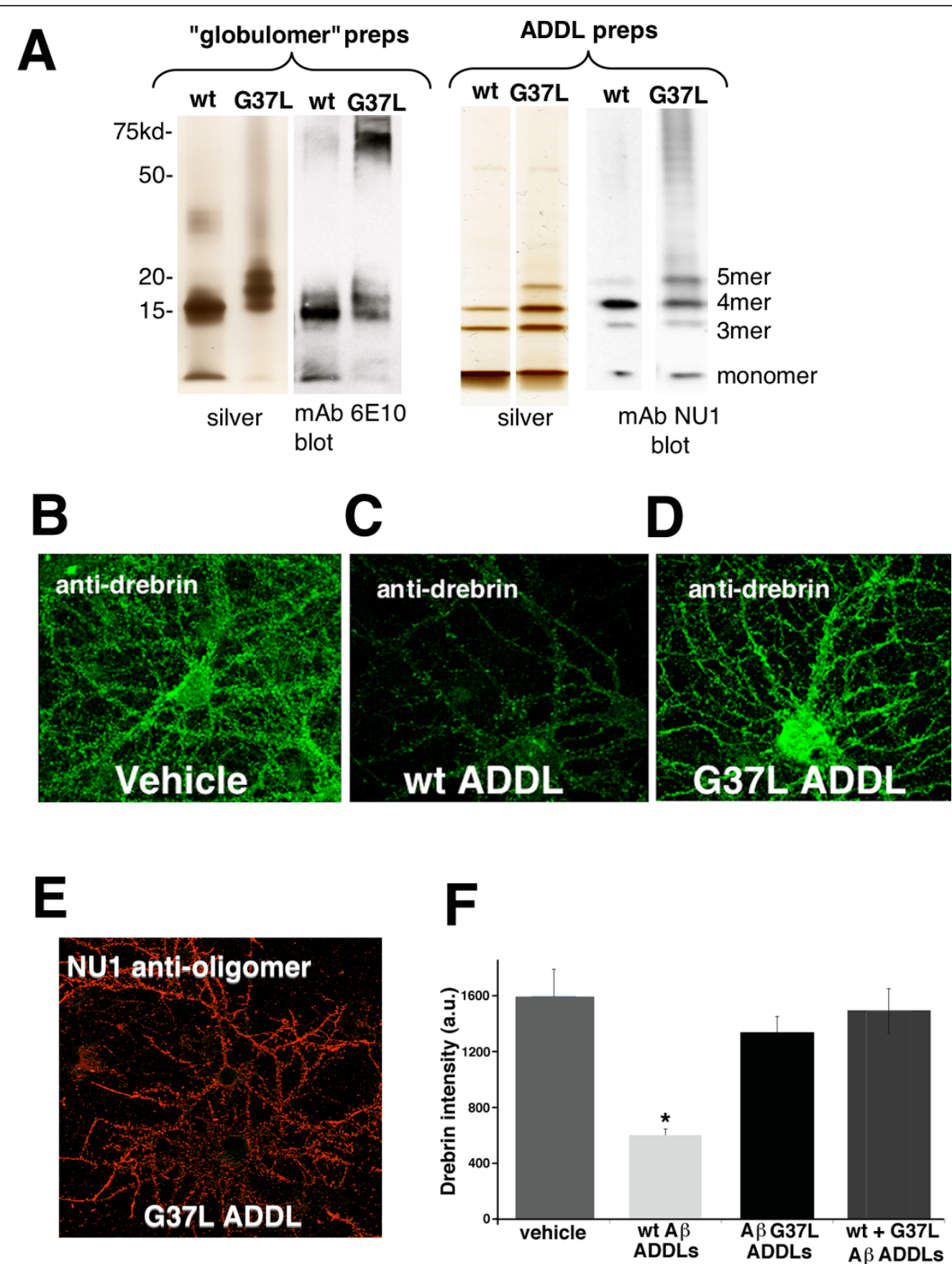

Figure 6 Toxicity of $A \beta$ wild type and $A \beta$ G37L oligomers (ADDLs) in primary hippocampal cultures. A. SDS-PAGE fractionation of oligomers formed from synthetic A $\beta 1-42$ wild type or G37L. The left panel displays oligomers formed using the "globulomer" preparation of Barghorn et al [21]. The right panel displays oligomers formed using the "ADDL" preparation originally described by Lambert et al [24].

Monoclonal antibody 6 E10 recognizes an epitope included in Aßresidues 16-24; mAb NU1 preferentially binds oligomeric A 3 . Note that for both oligomer preparations A $\beta$ G37L tends to form higher molecular weight species. B - D. Representative epifluorescence images of anti-drebrin staining of embryonic rat hippocampal neurons treated after 21 days in culture for $24 \mathrm{hr}$ with vehicle (B), $500 \mathrm{nM}$ A 3 wild type ADDLs (C), or $500 \mathrm{nM} \mathrm{A \beta}$ G37L ADDLs (D). Note the strong reduction of drebrin staining is induced by exposure to wild type, but not G37L, ADDLs. $\mathbf{E}$. Hippocampal neurons treated with AB G37 ADDLs, washed, fixed, and probed with anti-A $\beta$ oligomer antibody NU1. Note robust binding of the A $\beta$ G37L ADDLs to neurons. F. Quantification of drebrin immunoreactivity in hippocampal neurons exposed to A $\beta$ wild type or G37L ADDLs. Exposure to $A \beta$ wild type $A D D L s$ significantly reduced drebrin immunoreactivity relative to vehicle-treated neurons ( ${ }^{*} P<0.01$ ), but no significant reduction was found for $A \beta$ G37L ADDLs or ADDLs formed from a 1:1 mixture of A $\beta$ wild type and G37L (Tukey Multiple Comparisons test). 

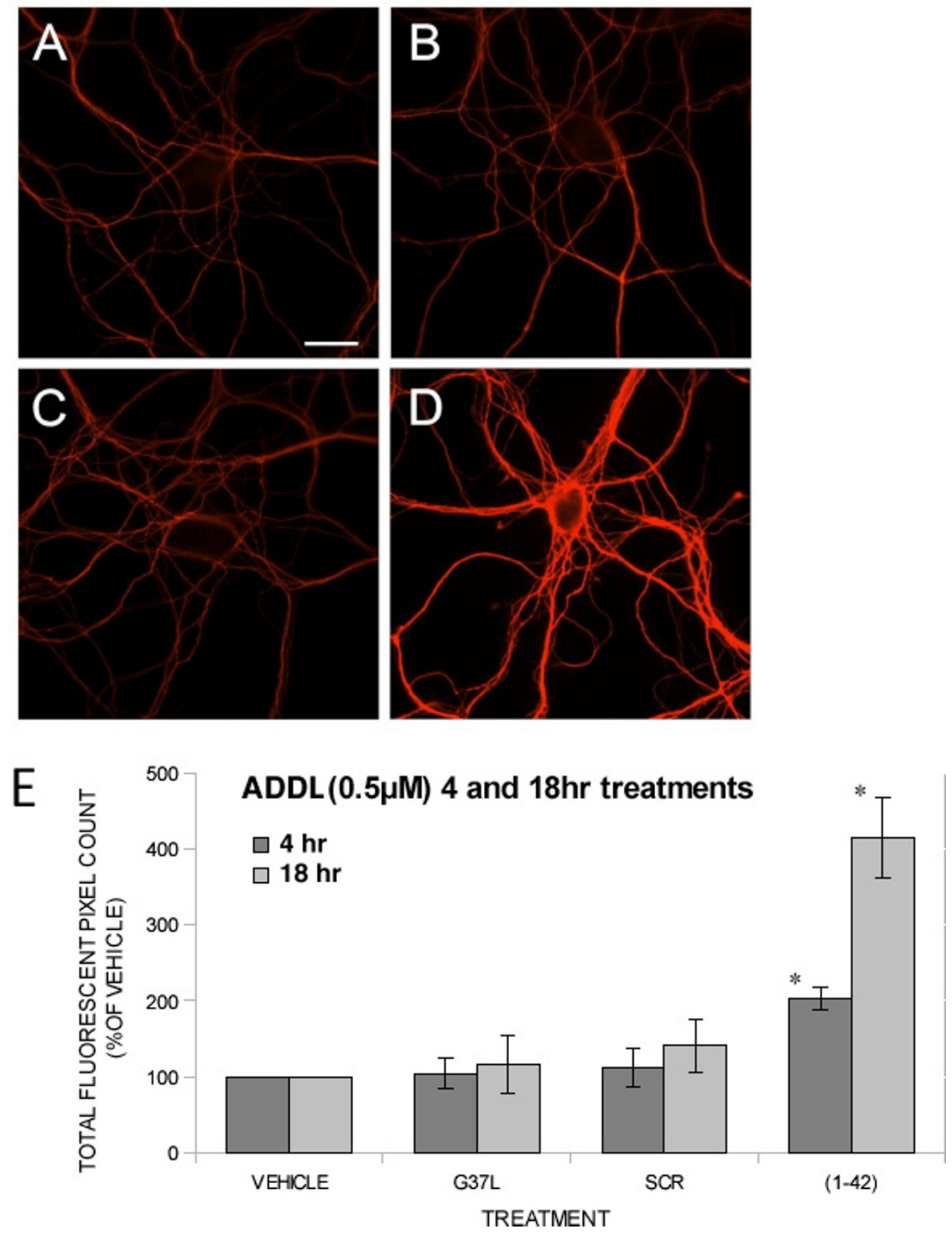

Figure 7 Effect of $\mathbf{A} \boldsymbol{\beta}$ wild type and G37L ADDL exposure on tau hyperphosphorylation. A. - D. Representative epifluorescence images of cultured embryonic hippocampal neurons that were exposed for $18 \mathrm{hr}$ to vehicle (A), $500 \mathrm{nM} \mathrm{A \beta}$ G37L ADDLs (B), $500 \mathrm{nM}$ A $\beta$ scrambled ADDLs (C), or $500 \mathrm{nM} \mathrm{A \beta}$ wild type ADDLs (D), then fixed and probed with anti-phospho tau monoclonal antibody PHF-1. Note strong increase in PHF1 staining only in neurons treated with $A \beta$ wild type ADDLs. E. Quantification of PHF-1 staining. Exposure to A $\beta$ wild type produced significant increases in PHF-1 staining relative to control at $4 \mathrm{hr}(204 \% \pm 13 ; \mathrm{p}=0.0023 ; \mathrm{n}=5)$ and $18 \mathrm{hr}(416 \% \pm 48 ; \mathrm{p}=0.0041 ; \mathrm{n}=5)$; none of the other treatments significantly increased PHF-1 staining (Student's T-test, ${ }^{*} P<0.005$ ). 
A

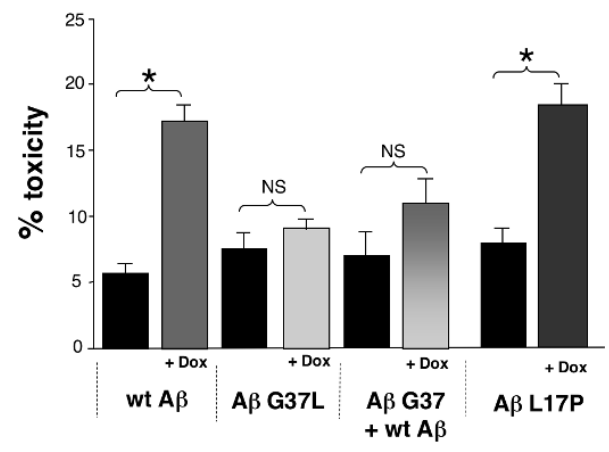

B
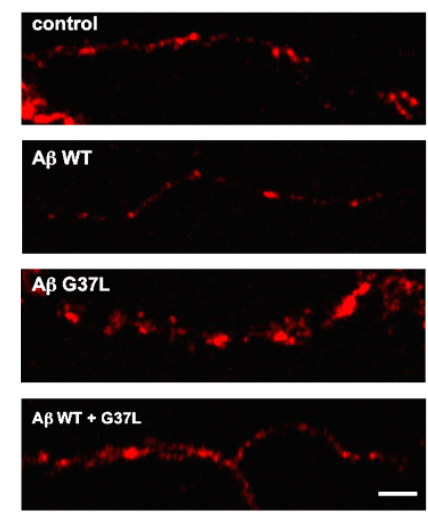

C

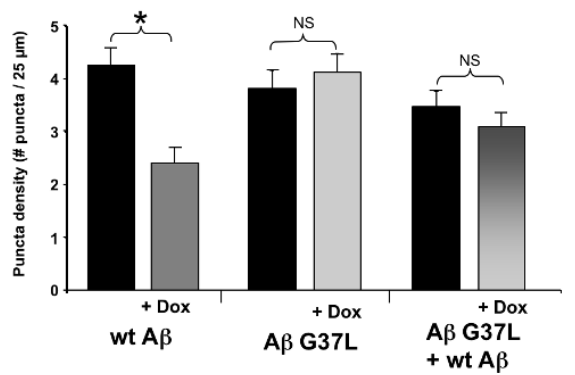

Figure 8 Toxicity of wild type and variant $A \beta$ in adenovirus transfection model. Cultured rat cortical neurons were transfected with adenovirus engineered for doxycycline-inducible expression of wild type or variant $A \beta$, and toxicity was assayed by scoring of apoptotic nuclei or synaptophysin expression. A. Relative toxicity (pyknotic nuclei fraction) in neurons transfected with $A \beta$-expressing adenovirus with (+ Dox) and without induction. Transfection with adenovirus expressing $A \beta$ wild type or A $\beta$ L17P leads to significant toxicity after transgene induction $\left({ }^{*} P<0.001\right)$, while transfection with adenovirus expressing $A \beta$ G37L, or co-transfection with $A \beta$ wild type and $A \beta$ G37L, does not lead to significant toxicity after doxycycline induction. B. Representative processes containing synapses labeled with synaptophysin in $A \beta$ wild type and $A \beta$ G37L expressing neuronal cultures. Control panel refers to non-induced cultures. Scale bar, 5 Hm. C. Analysis of puncta density (number of synapses per $25 \mu \mathrm{m}$ of neurite) indicated fewer synapses in $A \beta$ wild type expressing cells compared to non-induced controls.

Intraneuronal $A \beta$ G37L and co-expression of $A \beta$ wild type and $A \beta$ G37L resulted in no significant synapse alterations. Data from 3-5 different cultures from 3 independent isolations. $n$ (neurites) $=154$ A $\beta$ wild type, 98 A $\beta$ G37L, 118 A $\beta$ wild type $+\mathrm{G} 37 \mathrm{~L} .{ }^{*}=\mathrm{P}<0.001$, NS $=$ not significant, $P>0.1$ ). Error bars represent SEM. transfected with an adenovirus vector expressing $A \beta$ G37L did not show a significant increase in apoptotic nuclei after doxycycline induction, consistent with the reduced toxicity of this $A \beta$ variant. Co-transfection with both $\mathrm{A} \beta$ wild type and G37L-expressing adenovirus also failed to significantly increase the appearance of apoptotic nuclei relative to uninduced controls, again demonstrating the anti-toxic effects of $A \beta$ G37L expression. Interestingly, $A \beta$ L17P is as toxic as $A \beta$ wild type in this model, consistent with the A $\beta$ L17P toxicity observed in the transgenic $C$. elegans model.

As an alternative measure of $A \beta$ toxicity, we also assayed the effect of transfected $A \beta$ on synaptophysin, a well-studied presynaptic marker. As shown in Figure 8B, doxycycline induction of $A \beta$ wild type significantly reduces immuno-detectable synaptophysin. However, induction of transfected $A \beta$ G37L by itself or $A \beta$ G37L $+A \beta$ wild type does not result in statistically significant decreases in synaptophysin compared to uninduced controls (Figure $8 \mathrm{C}$ ), consistent with the anti-toxic effects of $A \beta$ G37L.

\section{Second site substitutions restore toxicity to $A \beta$ G37L}

A rigorous test of the glycine zipper model would be to determine if compensatory second site substitutions based on this model can restore toxicity to $A \beta$ G37L. In models of glycine zipper interactions in bacterial channel proteins, the glycine-containing face of a membrane $\alpha$-helix is opposed by the "backside" (i.e. opposite the glycine-containing face) of a neighboring $\alpha$-helix [13]. If this model were applied to the formation of membraneassociated $A \beta$ oligomers, $A \beta$ G37 would be predicted to interact with the non-glycine face of an $\alpha$-helix formed by a neighboring $A \beta$ molecule. The specific residues interacting with $A \beta$ G37 would therefore be those residing on the other side of the predicted $A \beta \alpha$-helix, which are potentially N27, I31, or M35 (see Figure 1). If the disruption of the glycine zipper by the G37L substitution is due to the larger leucine residue sterically hindering $\alpha$-helix packing, substituting a smaller amino acid opposite the leucine substitution could potentially compensate for the leucine substitution and thereby restore $\alpha$-helix packing and $A \beta$ toxicity. We therefore generated a set of transgenic worms expressing doubly-mutated A $\beta$ : N27G G37L; I31G G37L; and M35G G37L. As shown in Figure 9A, all these second site substitutions increased the toxicity of $A \beta$ G37L. $A \beta$ with single N27G, I31G, or M35G substitutions were not more toxic than $A \beta$ wild type (Figure 9B).

\section{Discussion}

Although the $\beta$-amyloid peptide is toxic in a wide range of model systems, the specific toxic form of $A \beta$ has not been convincingly identified, nor is it clear if the same 


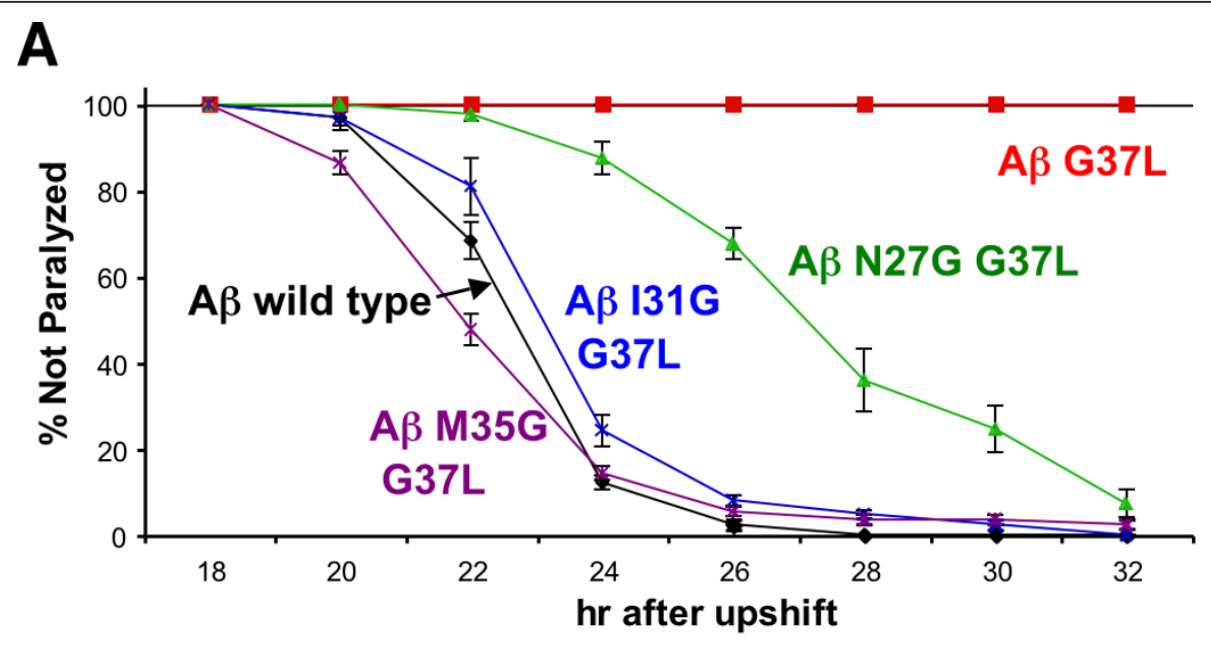

B

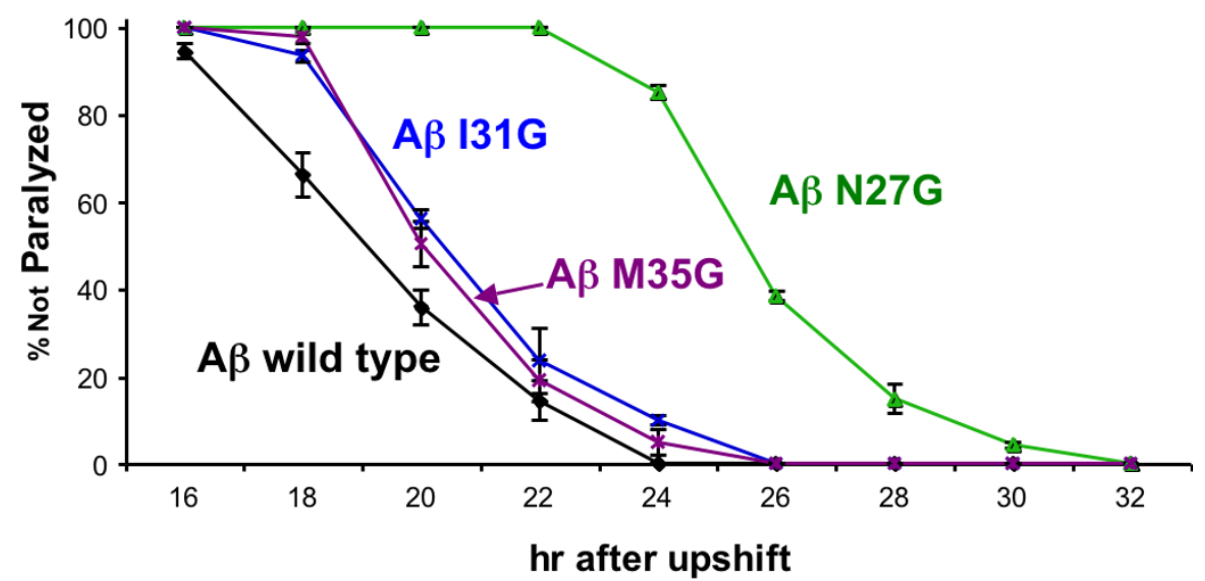

Figure 9 Second site mutations partially restore $\mathbf{A} \beta$ G37L toxicity. A. Paralysis plots of transgenic C. elegans expressing wild type, G37L, or double mutant $A \beta$. Note that the transgenic worms expressing the candidate compensatory mutations all paralyze faster than worms expressing A $\beta$ G37L. B. Paralysis plot of transgenic C. elegans expressing single compensatory mutations. None of these single site mutations confer obvious hyper-toxicity.

form of $A \beta$ is toxic in different model systems. Numerous studies have pointed to soluble, oligomeric $A \beta$ as being the key toxic species, but there is no general agreement about the subunit composition or quaternary structure of this toxic oligomer. Defining the toxic $A \beta$ species is difficult because while the oligomeric nature of $A \beta$ can be assayed before it is added to cells (e.g., size exclusion profiling of ADDLs prepared from synthetic $A \beta$ ) or after $A \beta$ is expressed (e.g., immunoblotting protein preparations from transgenic $A \beta$-expressing animals), capturing the toxic species "in action" has not been feasible. Direct biochemical approaches may also be problematic if the key $A \beta$ toxic species is unstable and/or a minor component of total $A \beta$. To avoid these problems we have assayed the toxicity, in vitro and in vivo, of a set of $\mathrm{A} \beta$ variants designed to test a specific model of the toxic $A \beta$ species. Our results demonstrate a critical role for $\mathrm{C}$-terminal glycine residues in the formation of toxic $A \beta$ oligomers, and thereby serve to significantly constrain structural models for these toxic oligomers.

We find that $A \beta$ G37L is less toxic than $A \beta$ wild type both in vivo and in primary neuronal culture. Our results are complementary to those of Harmeier et al [15], who showed that G33A or G33I substitutions also reduce $A \beta$ toxicity in vitro and in vivo. (These authors did not report testing G37 substitutions.) These combined studies strongly argue that it is the disruption of the glycine zipper itself, rather than the alteration of any specific residue, that reduces $A \beta$ toxicity.

How does $A \beta$ assemble into the toxic oligomeric species? A large fraction of $A \beta$ is membrane-associated 
both in the C. elegans model described here and in the AD brain (G. McColl and A. Bush, personal communication). We speculate that like a number of vertebrate antimicrobial peptides, $A \beta$ exists in a $\beta$-sheet or random coil configuration when soluble extracellularly or in the cytoplasm, but converts to an $\alpha$-helical structure upon membrane association. This conversion has been demonstrated by biophysical methods for plasticins [30,31] and bombinins [32], anti-microbial peptides that contain Gly-XXX-Gly-XXX-Gly motifs. Interestingly, $A \beta$ has also been shown to have anti-microbial activity [33]. While $\mathrm{x}$-ray crystal structures have not been determined for small anti-microbial peptides, the first atomic structure for an $\alpha$-helical pore-forming toxin (ClyA) has recently been described [34]. We note that this study reveals a $\beta$-sheet "tongue" present in the soluble form of ClyA that converts to $\alpha$-helical structure upon membrane insertion. This tongue region also contains a glycine zipper motif (...G ${ }^{180}$ AAAGVVAG $\left.^{188} \ldots\right)$, and a glycine-to-valine substitution at position 180 has been shown to compromise hemolytic activity of this toxin [35]. Thus, although ClyA is significantly larger than $A \beta$, these structural data are consistent with our model of $\alpha$-helix formation by the glycine zipper region of $A \beta$ occurring upon membrane association.

Our observation that $A \beta G 37 \mathrm{~L}$ does not form detectable amyloid in vivo differs from the results of Hung et al [14], who found that $A \beta$ G37L had enhanced fibrilization in vitro. These results can be reconciled if there are significant differences in the amyloid seeding step [36] under in vivo and in vitro conditions. It has been proposed that the formation of $\alpha$-helical structure by membrane-associated $A \beta$ drives the formation of oligomers and therefore a local increase in $A \beta$ concentration, and this localized $A \beta$ concentration catalyzes $\beta$-sheet formation and amyloid formation [37]. $\alpha$-helical intermediates have been observed preceding amyloid formation by $A \beta$ [38]. We suggest that in the C. elegans model, glycine zipper-driven oligomerization at membranes is required to reach the critical local $\mathrm{A} \beta$ concentration to initiate amyloid formation, and this oligomerization and subsequent amyloid formation is blocked by the G37L substitution. However, other interactions (perhaps influenced by overall peptide hydrophobicity) may drive the formation of initial amyloid seeds in vitro, and thus the glycine-substituted $A \beta$ peptides have faster amyloid formation rates under these conditions.

While A $\beta$ G37L appears anti-toxic in both Neuro-2a cells and primary hippocampal neurons, we did observe different co-incubation requirement for these two model systems: inhibition of wild type $A \beta$ toxicity required immediate co-oligomerization with $A \beta$ G37L in the Neuro-2a model but not in the primary neuronal culture model. One possible explanation for these differences is that $A \beta$ oligomers show highly preferential binding to synaptic sites in primary neurons [25], suggesting there may be a limiting number of $A \beta$ binding sites in these neurons. Consequently, unoligomerized $A \beta$ G37L may not only counter the toxic oligomerization of wild type $A \beta$, but oligomerized $A \beta$ G37L may also compete with wild type oligomers for binding to relevant sites on the neuronal plasma membrane. Competition for binding sites may not be relevant to $A \beta$ toxicity in the undifferentiated Neuro-2a cells used in our study.

Our demonstration of anti-toxic effects of $A \beta$ G37L in cell culture and primary neurons clearly supports the oligomer model for $A \beta$ toxicity, although we cannot readily infer the subunit composition of these oligomers from our experiments. We have observed variable patterns of presumed $A \beta$ oligomeric bands in strains expressing different $A \beta$ variants, but we have been unable to associate a specific oligomeric band with toxicity. A caveat to this approach to interpreting immunoblots is that we do not know to what degree they capture the true distribution of $\mathrm{A} \beta$ oligomers in vivo. It has been reported that different biophysical forms of $A \beta$ actually show similar oligomer banding patterns after SDS-PAGE [39].

Even though Kim et al have demonstrated that the G37L substitution blocks $A \beta$ channel formation in synthetic membranes, and we have rigorously demonstrated that $\mathrm{A} \beta \mathrm{G} 3 \mathrm{~L}$ has reduced toxicity in multiple models, at present we have no direct evidence that the reduced toxicity of $A \beta$ G37L is due to effects on membrane conductance per se. We also note that $A \beta$ need not form pores in order to disrupt membrane function; instead it could result from $A \beta$ altering the local membrane environment such that the conductance of endogenous ion channels (e.g., the NMDA receptor) is altered. An appealing component of the membrane disruption hypothesis is that it explains why $A \beta$ is toxic when both outside cells (e.g., hippocampal neurons exposed to ADDLs) and inside cells (e.g., intracellular accumulation in C. elegans): in either case, $A \beta$ has access to the plasma membrane. In theory, intracellular $A \beta$ could also damage organelle membranes, such as the ER or mitochondrial membranes. $A \beta$ accumulation has often been associated with mitochondrial dysfunction [40-42], and we have observed mitochondria with abnormal ultrastructure specifically in C. elegans muscles accumulating $\mathrm{A} \beta$ (Figure 2). Given that we did not observe abnormal mitochondria in transgenic worms expressing $A \beta$ G37L, we speculate that expression of wild type $A \beta$ in this model may lead to disruption of mitochondrial membrane function.

Introduction of second site mutations into $A \beta$ G37L resulted in enhanced toxicity. This compensatory interaction is most striking in the N27G G37L variant, which 
is clearly more toxic than either single substitution (see Additional file 1 Figure S2). However, interpretation of the enhanced toxicity in $A \beta$ I31G G37L and A $\beta$ M35G G37L relative to $A \beta$ G37L is complicated by the observation that the single $A \beta$ I31G and $A \beta$ M35G strains produce reduced levels of $A \beta$ relative to the control $A \beta$ wild type strain but show comparable paralysis rates, suggesting these single substitutions may be more toxic than wild type $A \beta$. If this is the case, we cannot exclude the possibility that these second site mutations increase the toxicity of $A \beta$ G37L by an additive rather than compensatory mechanism. If the correct interpretation is that these second site mutations all increase toxicity by restoring helix packing in the glycine zipper region, our results imply that there is no single packing arrangement involved in the formation of toxic $A \beta$ oligomers, as all three of the tested second site substitutions enhanced the toxicity of $A \beta$ G37L. An alternative explanation for the enhanced toxicity of the double mutant $A \beta$ is that it is the total number of glycine residues in the C-terminal region of $A \beta$ that is the key determinant of toxicity. Although we cannot exclude this possibility, it is difficult to develop a molecular model that would account for this explanation.

We did undertake multiple attempts to generate transgenic worms with a leucine substitution at the single glycine residue in $A \beta$ that lies outside the glycine zipper region (G9), which we predicted would not reduce toxicity. Unfortunately, all of the chromosomally-integrated transgenic lines recovered in this series of experiments did not produce detectable $A \beta$, an experimental failure that did not occur for any of the other glycine substitutions we attempted. It has also been more difficult to recover transmitting lines expressing wild type $A \beta$, presumably due to selection against lines expressing this toxic peptide (even under non-induced conditions). Thus, while we do not have data for the G9L control, we speculate that this variant may be at least as toxic as wild type $A \beta$.

Although $A \beta$ G37L appears to be significantly less toxic than wild type $A \beta$ when expressed in C. elegans, it does not appear to be non-toxic, as transgenic worms expressing A $\beta$ G37L still ultimately become paralyzed. A possible explanation for this observation is that there may be two components to $A \beta$ toxicity in this $C$. elegans model: a specific toxicity due to activity of $A \beta$ oligomers, and a more general toxicity due to accumulation of misfolded protein. There is strong evidence that accumulation of misfolded proteins in C. elegans muscle can lead to a disruption of cellular protein handling (proteostasis) $[43,44]$, and expression of an aggregationprone polyglutamine::YFP fusion protein in C. elegans muscle leads to reduced motility [45]. A $\beta$ G37L and the other variants examined in this study all make immunoreactive cytoplasmic inclusions when expressed in C. elegans muscle, consistent with our transgenic inducible system generally producing $A \beta$ levels that exceed cellular protein handling capacity.

Our studies predict that compounds that specifically interfere with $A \beta$ glycine zipper formation will block $A \beta$ toxicity, and therefore would be candidate therapeutics for Alzheimer's disease. Computational methods exist to design peptides that specifically disrupt helix-helix interactions in protein transmembrane regions [46,47]; in theory this approach can be used to target the $A \beta$ glycine zipper. Extending this approach to develop practical therapeutic compounds for Alzheimer's disease will likely require identification of brain-accessible small molecules that specifically inhibit $A \beta$ glycine zipper interactions. Our studies also suggest the possibility that there may exist in the human population alleles of APP that encode substitutions in the glycine zipper regions that protect against Alzheimer's disease.

\section{Methods \\ Construction and characterization of transgenic C. elegans strains}

Transgenic constructs designed to produce temperatureinducible expression of substituted $A \beta$ in C. elegans body wall muscle were generated from expression construct pCL12 (Pmyo-3::signal peptide::A $\beta$ 1-42::Iong 3' UTR) [18]. The inclusion of an abnormally long 3' untranslated region in this construct leads to transgene expression being regulated by the mRNA surveillance system. Introduction of pCL12-derived transgenes into a genetic background containing a temperature-sensitive mutation in an essential RNA surveillance gene [smg-1 (cc546)] results in increased transgene expression at non-permissive temperatures. Transgenes expressing variant $A \beta$ were typically generated by in vitro mutagenesis [Gene Tailor kit (Invitrogen) or Site Directed Mutagenesis Kit (Stratagene)] of the signal peptide::A $\beta$ 1-42 minigene cassette in a donor plasmid. The mutated $A \beta$ minigene was then used to replace the wild type $A \beta$ minigene sequence in pCL12 by restriction enzyme cleavage (Nhe I/Sac I) and religation. A transgene with muscle expression of GFP::A $\beta$ G37L was similarly constructed by in vitro mutagenesis of pCL111 (Pmyo3::GFP::A $\beta$ 3-42). All plasmid constructs were confirmed by DNA sequencing.

C. elegans strains containing multicopy, chromosomally-integrated transgenes were constructed as previously described [18]. Briefly, $A \beta$ expression plasmids (100 $\mathrm{ng} / \mu \mathrm{l}$ final concentration) were co-microinjected with marker plasmids $[100 \mathrm{ng} / \mu \mathrm{l}$ final concentration of either pRF4 expressing dominant Roller morphological marker rol-6 (su1006) or pCL26 expressing constitutive intestinal GFP (Pmtl-2::GFP)] into smg-1(cc546) worms. 
Transmitting strains were initially recovered containing unstable extrachromosomal transgenes, and then strains were derived containing fully stable chromosomally-integrated transgenes by irradiation and subsequent selection (5). PCR and subsequent DNA sequencing was performed to check the $A \beta$ genotype of transgenic strains.

\section{Paralysis assays}

Quantification of paralysis rates for transgenic C. elegans strains was done as previously described $[48,49]$. Briefly, populations of third larval stage transgenic worms were upshifted from $16^{\circ} \mathrm{C}$ to $25^{\circ} \mathrm{C}$ and the fraction of paralyzed fourth larval stage worms was scored every $2 \mathrm{hr}$ starting 12-18 hr after upshift (depending on transgenic strains assayed). Triplicate populations (total $n>100$ ) were scored for each genotype in a paralysis assay, and each paralysis assay was repeated at least three times. Transgenic strains containing the rol-6 morphological marker (which affects overall worm movement) reproducibly showed slower absolute paralysis rates compared to transgenic strains expressing the same $A \beta$ construct but a GFP transgenic marker. All strain paralysis comparisons were therefore made between transgenic strains using the same marker transgene.

\section{Quantification of $A \beta$ expression in transgenic C. elegans}

To quantify $\mathrm{A} \beta$ accumulation in $C$. elegans (Supplemental Table 1), transgenic populations were harvested 24 $\mathrm{hr}$ after temperature upshift, and whole worm extracts were fractionated by SDS-PAGE as previously described [50]. After blotting, the fractionated proteins were probed with anti-A $\beta$ monoclonal antibody $6 \mathrm{E} 10$ (Abcam, \#Ab10146) at $0.7 \mu \mathrm{g} / \mathrm{ml}$, and $A \beta$ immunoreactivity was visualized using HRP-conjugated secondary antibodies (1:1000 dilution), ECL development (GE Osmonics), and digital image acquisition (Image Station 2000R, Kodak). Total $A \beta$ immunoreactivity was quantified using Image J software to sum whole-lane immunoreactivity (i.e., all oligomeric and monomeric bands as illustrated in Figure $2 C)$. A $\beta$ immunoblot expression was normalized to either CSTF64 (a ubiquitous, highly-expressed splicing factor) immunoreactivity or total blotted proteins assayed by Ponceau $\mathrm{S}$ staining.

\section{C. elegans electron microscopy}

Staged populations of transgenic C. elegans were shifted as third larval stage worms from $16^{\circ} \mathrm{C}$ to $25^{\circ} \mathrm{C}$ for $24 \mathrm{hr}$, then immediately harvested and subjected to high pressure freeze fixation as previously described [51].

\section{Culture and treatment of $\mathrm{N} 2 \mathrm{a}$ cells}

Neuro2a mouse neuroblastoma cells (N2a) were grown in a 1:1 mixture of OptiMEM-I and DMEM (containing GlutaMax and nonessential amino acids), supplemented with $10 \%$ FBS. The cells were plated in poly-L-lysinecoated 96 well plates at 10,000 cells/well in $100 \mu \mathrm{L}$ medium. Two days later, the cells were treated with wild type (wt) and/or mutant (G37L) A $\beta 42$ peptides for 24 hours, whereupon their toxicity was assessed as a decrease in the metabolic reduction of MTT (3-(4,5Dimethylthiazol-2-yl)-2,5-diphenyltetrazolium bromide) to formazan. Briefly, $10 \mu \mathrm{l}$ aliquots of MTT $(5 \mathrm{mg} / \mathrm{ml}$ in sterile PBS) were added to each well of cells for $2-4 \mathrm{hr}$ at $37^{\circ} \mathrm{C}$, the reaction was stopped by adding $100 \mu \mathrm{l} 20 \%$ SDS in $50 \% \mathrm{~N}, \mathrm{~N}$-dimethylformamide to each well, the plates were incubated at $37^{\circ} \mathrm{C}$ overnight to dissolve the purple formazan, and the absorbance was read at 560 $\mathrm{nm}$. Frozen, dried preparations of monomerized $A \beta-\mathrm{wt}$ and $A \beta-G 37 L$ peptides were dissolved in DMSO at 1 $\mathrm{mM}$, diluted to $100 \mu \mathrm{M}$ with OptiMEM-I, and immediately combined with additional vehicle, and/or with each other, to form mixtures that contained one or both peptides at a concentration of $25 \mu \mathrm{M}$ each. These were allowed to sit at room temperature for $20 \mathrm{~min}$, before being added to the cells at a final concentration of 4 $\mu \mathrm{M}$ for each peptide. In this way, N2a cells were exposed to either $4 \mu \mathrm{MA} \beta$-wt, $4 \mu \mathrm{M} A \beta$-G37L, a combination of $4 \mu \mathrm{M} A \beta$-wt plus $4 \mu \mathrm{M} A \beta$-G37L that had been incubated together for $20 \mathrm{~min}$, or a combination of $4 \mu \mathrm{M} \mathrm{A} \beta$-wt plus $4 \mu \mathrm{M} \mathrm{A} \beta$-G37L that had been incubated separately for $20 \mathrm{~min}$ before being added to the cells together. In a variation of this protocol, the amount of A $\beta$-G37L peptide that was pre-incubated with $25 \mu \mathrm{M}$ $\mathrm{A} \beta$-wt was varied from $0-25 \mu \mathrm{M}$ to determine how much $A \beta-G 37 \mathrm{~L}$ was needed to counteract the toxicity of $\mathrm{A} \beta$-wt peptide (applied to N2a at $4 \mu \mathrm{M}$ ). The amount of DMSO in the medium was the same $(0.4 \%)$ for all samples and controls. In each experiment 4-6 wells were analyzed per treatment, and each experiment was repeated at least 3 times.

\section{Exposure of hippocampal neurons to ADDLs}

Preparation of oligomeric $A \beta$. A $\beta$ oligomers (ADDLs) were generated from synthetic $A \beta$ essentially as previously described $[24,25]$. Synthetic $A \beta$ peptide was obtained from the following sources: $A \beta 1-42$ and $A \beta 1$ 42 G37L from American Peptide Company Inc., Sunnyvale, $C A$; scrambled $A \beta \quad 1-42$ and fluorescein amiditetagged A 1-42 from AnaSpec, San Jose, CA; and additional A $\beta$ 1-42 G37L from Biosynthesis, Lewisville, TX. Peptides were prepared as dried HFIP films, then dissolved in fresh, anhydrous DMSO (Sigma Hybri-Max D2650 ) to make a $\sim 5 \mathrm{mM}$ solution then diluted to $\sim 100$ $\mu \mathrm{M}$ with cold F12 media without phenol red (Biosource) and aged $24 \mathrm{hr}$ at $4^{\circ} \mathrm{C}$. The samples were centrifuged at $14,000 \mathrm{~g}$ for $10 \mathrm{~min}$ at $4^{\circ} \mathrm{C}$ and the supernatants stored at $4^{\circ} \mathrm{C}$. Protein concentration was determined by Coomassie Plus protein assay (Pierce) with a BSA standard.

Gel electrophoresis of oligomerized $A \beta$ Samples were diluted in F12 and mixed 1:1 with Laemmli sample buffer (Bio-Rad) and electrophoresed at $125 \mathrm{~V}$ on a $4-20 \%$ Tris-glycine gel (Novex, Invitrogen) with Tris-glycine- 
SDS buffer (Bio-Rad) at room temperature (RT) for 100 min. The gel (45 pmoles/lane) was silver stained with SilverXpress (Invitrogen). Alternatively, the gel (15 pmoles/lane) was electroblotted onto Hybond ECL nitrocellulose using $25 \mathrm{mM}$ Tris, $192 \mathrm{mM}$ glycine, 20\% methanol, $0.02 \%$ SDS, pH 8.3 at $100 \mathrm{~V}$ for $1 \mathrm{hr}$ at $4^{\circ} \mathrm{C}$. The blot was blocked with $5 \%$ non-fat dry milk in TBS$\mathrm{T}(0.1 \%$ Tween-20 in $20 \mathrm{mM}$ Tris- $\mathrm{HCl} \mathrm{pH} \mathrm{7.5,} \mathrm{0.8 \%}$ $\mathrm{NaCl})$ for $45 \mathrm{~min}$ at RT, incubated with NU1 $(1 \mathrm{mg} / \mathrm{ml}$ in milk/TBS-T) for $2 \mathrm{hr}$ at RT and washed 3 times with TBS-T. The blot was incubated with HRP-linked antimouse IgG (1:40,000 in milk/TBS-T; Amersham) for 60 min at RT, washed 3 times with TBS-T, rinsed 3 times with $\mathrm{dH}_{2} \mathrm{O}$, developed with SuperSignal West Femto Maximum Sensitivity substrate (Pierce) for $1 \mathrm{~min}$ and read on a Kodak Image Station.

Preparation of primary hippocampal cultures Hippocampi from embryonic day 18 Sprague-Dawley rats were used for the preparation of primary hippocampal cultures. For the drebrin expression experiments, cultures were prepared as previously described by Gong et al [22], and cultured neurons were exposed to ADDLs at 21 D.I.V. For the tau phosphorylation experiments, the primary cultures were prepared as described by Decker et al [52], and the cultures were exposed to ADDLs at 9 D.I.V.

Detection of $A \beta$ binding to hippocampal neurons ADDLs bound to mature hippocampal neurons were detected using monoclonal antibody NU1 [53] or by preparing fluorescent ADDLs (FADDLs) using biotinylated $A \beta$ and streptavidin-conjugated quantum dots [54]. Immunocytochemistry, image acquisition, and analysis for drebrin expression

The drebrin expression assay was performed as previously described [26]. Briefly, mature hippocampal cells at 21 DIV are treated with the fluorescently tagged ADDLs (FADDLs) for $24 \mathrm{hr}$. Treated cells were rinsed to remove unbound $A \beta$-assemblies and then fixed with $3.7 \%$ formaldehyde or $4 \%$ paraformaldehyde in Neurobasal media (1:1 volume) for $20 \mathrm{~min}$ followed by an additional $20 \mathrm{~min}$ undiluted fixative. Cells were rinsed extensively in PBS. Cover slips were incubated in blocking solution $(10 \%$ normal goat serum in PBS without $0.1 \%$ Triton X-100) for $45 \mathrm{~min}$ at room temperature (RT). Antibody against drebrin (Stressgen, Victoria, British Columbia, Canada) was used to identify dendritic spines. It was diluted in blocking solution and incubated on the cells overnight at $4^{\circ} \mathrm{C}$. After rinses with PBS with $1 \%$ NGS, cover slips were incubated with appropriate Alexa-Fluor-conjugated secondary antibodies (Invitrogen, Carlsbad, CA) diluted in PBS plus 1\% NGS for 90 min at RT, rinsed extensively in PBS, and mounted with ProLong Anti-fade media (Invitrogen).
$A \beta$ oligomer-bound neurons and dendritic branches were imaged using a Leica (Exton, PA) TCS SP2 laser confocal microscope with laser intensity and signal detection settings held constant to allow for quantitative comparison between experimental groups. Optical serial sections of $0.5 \mu \mathrm{m}$ intervals were taken through the cells and reconstructed to generate a maximum intensity projection of $z$-stack images from individual cells and dendritic branches. After setting the intensity threshold, dendritic segments of determined length were used to determine drebrin integrated fluorescence intensity. Spine Quantification was done using MetaMorph software version 6.3 (Universal Imaging Corporation, Downingtown, PA). All data are depicted as mean+/-SEM and were analyzed by GraphPad Prism4 software (San Diego, CA) for statistical significance using one-way ANOVA and, if overall $p<0.05$, followed by a multiple group comparison post hoc test (Tukey's).

Immunocytochemistry, image acquisition, and analysis for tau phosphorylation

Neurons were fixed with a solution of $4 \%$ paraformaldehyde $/ 4 \%$ sucrose in PBS for 15 minutes, rinsed two times in PBS and permeabilized for 7 minutes with Triton X$100(0.25 \%)$ in PBS. The permeabilization solution was removed by rinsing three times in PBS. To prevent nonspecific binding of antibodies cells were incubated with a Fish Skin Gelatin blocking buffer (FSGB) containing Fish Skin Gelatin (0.5\%) (Sigma-Aldrich) and Triton X-100 $(0.1 \%)$ in PBS. Neurons were double immunolabeled by overnight incubation at $4^{\circ} \mathrm{C}$ with mouse anti-PHF-1 (Ser396/404) (1:300) (provided by D. Volcado, Simon Fraser University, Burnaby, Canada) and rabbit antiMAP2 (1:500) (Millipore, Temecula, CA) primary antibodies, diluted in FSGB. The cells were rinsed 3 times in PBS and incubated for 2 hours at $37^{\circ} \mathrm{C}$ with $\mathrm{Cy}-3$ conjugated donkey anti-mouse IgG (1:500) (Jackson ImmunoResearch Laboratories Inc., West Grove, PA) and Alexa Fluor 488 goat anti-rabbit IgG (1:500) (Invitrogen) secondary antibodies, diluted in FSGB. Cells were rinsed 3 times with PBS and twice with Milli-Q water to remove buffer salts. Cover slips were mounted with Hoechst $33258(10 \mu \mathrm{g} / \mathrm{ml})$ (Sigma-Aldrich) in Elvanol.

Fluorescence imaging was carried out using a Leica DMI 6000B microscope (Leica Microsystems Inc., Richmond Hill, Canada) with a $63 \times 1.4$ plan apochromat objective (Leica Microsystems Inc.). Images were obtained with a cooled Orca-ER CCD camera (Hamamatsu Photonics, Bridgewater, NJ) controlled by MetaMorph (Molecular Devices, Sunnyvale, CA). Due to limitations in the digitizing range of the camera, pictures of treated specimens and controls sometimes had to be taken with different exposure times to avoid saturation of the maximum pixel value. The results were 
normalized for this difference during the quantitative analysis. Quantification of differences in tau phosphorylation was performed using Image J (NIH; Windows Version) essentially as described [27]. In brief, an appropriate threshold was applied to eliminate background signal before image analysis. Eighteen images per experimental condition were analyzed and at least two experiments using independent cultures were performed. Changes in tau phosphorylation were estimated by comparison of total fluorescent pixel counts and the results were combined for each condition. The total fluorescent pixel counts were normalized by the number of cell bodies in each image and by any difference in exposure times. Statistical testing was carried out using Microsoft Excel. Where applicable a student's unpaired t-test was performed. The mean value of 18 images from one experiment constituted one sample (n). An a level of 0.01 was used. Values for changes in tau phosphorylation are presented as mean \pm standard error of the mean (SEM). Data for A $\beta$ 1-42 oligomers $(0.5 \mu \mathrm{M})$ at 4 and 18 hours were provided by H. Decker, Simon Fraser University, Burnaby, Canada.

\section{Adenovirus transfections and experimental analysis - Antibodies}

Anti-synaptophysin (Chemicon International, Temecula, CA) was used at a 1:250 dilution.

\section{Adenoviral vector construction}

The AdTet-On, AdTRE-LacZ, and AdTRE-A $\beta 42$ viruses were previously described [28], G37L A $\beta 42$ mutation was introduced by site-directed mutagenesis into the original pTRE-A $\beta 42$ vector; the TRE cassette was subcloned into pShuttle vector, and recombination with pAdEasy-1 vector was achieved following manufacturer's instructions (Quantum Biotechnologies, Montreal, Quebec, Canada). Recombinant, E1-deleted replicationdefective adenoviral constructs were produced [30]. Viral titer was determined by cell death assay.

\section{Neuronal cultures}

For rat primary cultures, cortices were dissected from embryonic day 18 Sprague Dawley rat brains (Charles River Laboratories, Wilmington, MA), and neurons were prepared as described previously [28]. Primary cortical cultures were infected 11-13 days after plating at final multiplicities of infection (m.o.i.) of 500. Equal amounts of $A \beta 42-W T$ and $A \beta 42-G 37 L$ viruses were used when added simultaneously. AdTet-On and AdTRE adenoviral vectors were added into culture for $18 \mathrm{~h}$ at a 1:5 ratio, and transgene expression was induced by $1 \mu \mathrm{g} / \mathrm{ml}$ doxycycline (Dox; Sigma) for $24 \mathrm{~h}$. Efficiencies of transfection of $>70 \%$ were achieved.

\section{Immunofluorescence}

Cells were grown on poly-ornithine ( $3 \mu \mathrm{g} / \mathrm{ml}$; Sigma) and laminin ( $5 \mu \mathrm{g} / \mathrm{ml}$; Invitrogen, Carlsbad, CA) coated cover slips, washed once in PBS, and fixed in $3 \%$ paraformaldehyde in phosphate buffer as described previously [28]. The percentage of pyknotic nuclei was obtained by counting 20 random fields per sample at $40 \times$ as described [28], in each of 7-13 different cultures from 3 independent isolations. To analyze the effects of A 342 on synapses, images were collected in a Leica TCS SP5 Confocal Microscope (Leica Microsystems Inc., Bannockburn, IL) using a $63 \times$ lens, a standard pinhole of 1 , optical intervals of $0.5 \mu \mathrm{m}, 16$-bit depth resolution, and with equal exposure times. MetaMorph software (Universal Imaging, West Chester, PA) was used for quantitative analysis. Threshold was set at least $2 \times$ above background levels. To analyze synaptic density (referred to as the number of synapses present in a given neurite segment) at least 5 random fields were imaged from each neuronal culture (3-5 different cultures from 3 independent isolations).

\section{Statistical analysis}

Statistical significance was determined by the Student's two-tailed, unpaired t test, and a $\mathrm{p}$ value $<0.05$ was considered indicative of a significant difference. All bar graphs are expressed as SEM.

\section{Additional material}

Additional file 1: "A $\beta$ expression in transgenic strains and doseresponse toxicity analysis for $A \beta$ oligomers in hippocampal neurons." This file contains measurements of relative $A \beta$ expression and toxicity for all transgenic nematode strains used in this study (Table S1 and Figure S2) and quantification of drebrin expression in hippocampal neurons exposed to different levels of $A \beta$ wild type or $G 37 L$ oligomers.

\section{List of abbreviations}

Aß: $\beta$-amyloid peptide; N2a: Neuro2a; MTT: (3-(4,5-Dimethylthiazol-2-yl)-2,5diphenyltetrazolium bromide): SEM: Standard Error of the Mean.

\section{Acknowledgements}

We would like to thank Hilary Devlin for assistance with media preparation. Some nematode strains were provided by the Caenorhabditis Genetics Center, funded by the NIH National Center for Research Resources. This work was supported by an Alzheimer's Association Zenith Award (C.D.L), NIH award AG12423 (C.D.L), and Canadian Institutes for Health Research, Grant \# 102686 (M.A.S.).

\section{Author details}

${ }^{1}$ Institute for Behavioral Genetics, University of Colorado, Boulder, CO 80309, USA. ${ }^{2}$ Neurobiology and Physiology Department, Northwestern University, Evanston, IL, 60208, USA. ${ }^{3}$ Department of Neurology and Neuroscience, Weill Medical College of Cornell University, New York, NY 10065, USA.

${ }^{4}$ Department of Biological Sciences, Simon Fraser University, Burnaby, British Columbia V5A 1S6, Canada. ${ }^{5}$ Department of Molecular, Cellular, and Developmental Biology, University of Colorado, Boulder, CO 80309, USA. ${ }^{6}$ Integrative Physiology, University of Colorado, Boulder, CO 80309, USA.

\section{Authors' contributions}

C. elegans experiments were performed by VF, VD, CMR, PG, and CDL. Neuro $2 \mathrm{a}$ experiments were performed by GHS and ADDL-treated hippocampal were analyzed by PL. (oligomer binding and drebrin expression) and ND, EYF and MAS (tau phosphorylation). Adenovirus transfection of cortical 
neurons was performed by JM GHS, PL, MAS, JM and CDL prepared the manuscript. All authors have read and approved the final manuscript.

\section{Competing interests}

The authors declare that they have no competing interests.

Received: 10 June 2011 Accepted: 23 August 2011

Published: 23 August 2011

\section{References}

1. Hardy J, Selkoe DJ: The amyloid hypothesis of Alzheimer's disease: progress and problems on the road to therapeutics. Science 2002, 297:353-356.

2. Pappolla MA, Sos M, Omar RA, Bick RJ, Hickson-Bick DL, Reiter RJ, Efthimiopoulos S, Robakis NK: Melatonin prevents death of neuroblastoma cells exposed to the Alzheimer amyloid peptide. J Neurosci 1997, 17:1683-1690.

3. Hertel C, Terzi E, Hauser N, Jakob-Rotne R, Seelig J, Kemp JA: Inhibition of the electrostatic interaction between beta-amyloid peptide and membranes prevents beta-amyloid-induced toxicity. Proc Natl Acad Sci USA 1997, 94:9412-9416.

4. Yankner BA, Duffy LK, Kirschner DA: Neurotrophic and neurotoxic effects of amyloid beta protein: reversal by tachykinin neuropeptides. Science 1990, 250:279-282

5. Link CD: Expression of human beta-amyloid peptide in transgenic Caenorhabditis elegans. Proc Natl Acad Sci USA 1995, 92:9368-9372.

6. Hsiao K, Chapman P, Nilsen S, Eckman C, Harigaya Y, Younkin S, Yang F, Cole G: Correlative memory deficits, Abeta elevation, and amyloid plaques in transgenic mice. Science 1996, 274:99-102.

7. Oddo S, Caccamo A, Shepherd JD, Murphy MP, Golde TE, Kayed R, Metherate R, Mattson MP, Akbari Y, LaFerla FM: Triple-transgenic model of Alzheimer's disease with plaques and tangles: intracellular Abeta and synaptic dysfunction. Neuron 2003, 39:409-421.

8. lijima K, Liu HP, Chiang AS, Hearn SA, Konsolaki M, Zhong Y: Dissecting the pathological effects of human Abeta40 and Abeta42 in Drosophila: a potential model for Alzheimer's disease. Proc Natl Acad Sci USA 2004, 101:6623-6628.

9. Podlisny MB, Walsh DM, Amarante P, Ostaszewski BL, Stimson ER, Maggio JE, Teplow DB, Selkoe DJ: Oligomerization of endogenous and synthetic amyloid beta-protein at nanomolar levels in cell culture and stabilization of monomer by Congo red. Biochemistry 1998, 37:3602-3611.

10. Lambert MP, Barlow AK, Chromy BA, Edwards C, Freed R, Liosatos M, Morgan TE, Rozovsky I, Trommer B, Viola KL, Wals P, Zhang C, Finch CE, Krafft GA, Klein WL: Diffusible, nonfibrillar ligands derived from Abeta1-42 are potent central nervous system neurotoxins. Proc Natl Acad Sci USA 1998, 95:6448-6453.

11. Kayed R, Head E, Thompson UL, McIntire TM, Milton SC, Cotman CW, Glabe CG: Common structure of soluble amyloid oligomers implies common mechanism of pathogenesis. Science 2003, 300:486-489.

12. Arispe N, Pollard HB, Rojas E: Zn2+ interaction with Alzheimer amyloid beta protein calcium channels. Proc Natl Acad Sci USA 1996, 93:1710-1715.

13. Kim S, Jeon TJ, Oberai A, Yang D, Schmidt JJ, Bowie JU: Transmembrane glycine zippers: physiological and pathological roles in membrane proteins. Proc Natl Acad Sci USA 2005, 102:14278-14283.

14. Hung LW, Ciccotosto GD, Giannakis E, Tew DJ, Perez K, Masters CL, Cappai R, Wade JD, Barnham KJ: Amyloid-beta peptide (Abeta) neurotoxicity is modulated by the rate of peptide aggregation: Abeta dimers and trimers correlate with neurotoxicity. J Neurosci 2008, 28:11950-11958.

15. Harmeier A, Wozny C, Rost BR, Munter LM, Hua H, Georgiev O, Beyermann M, Hildebrand PW, Weise C, Schaffner W, Schmitz D, Multhaup G: Role of amyloid-beta glycine 33 in oligomerization, toxicity, and neuronal plasticity. J Neurosci 2009, 29:7582-7590.

16. Munter LM, Botev A, Richter L, Hildebrand PW, Althoff $V$, Weise C, Kaden D, Multhaup G: Aberrant amyloid precursor protein (APP) processing in hereditary forms of Alzheimer disease caused by APP familial Alzheimer disease mutations can be rescued by mutations in the APP GxxxG motif. J Biol Chem 2010, 285:21636-21643.

17. Munter LM, Voigt $P$, Harmeier A, Kaden D, Gottschalk KE, Weise C, Pipkorn R, Schaefer M, Langosch D, Multhaup G: GxxxG motifs within the amyloid precursor protein transmembrane sequence are critical for the etiology of Abeta42. EMBO J 2007, 26:1702-1712.

18. Link CD, Taft A, Kapulkin V, Duke K, Kim S, Fei Q, Wood DE, Sahagan BG: Gene expression analysis in a transgenic Caenorhabditis elegans Alzheimer's disease model. Neurobiol Aging 2003, 24:397-413.

19. Fay DS, Fluet A, Johnson CJ, Link CD: In vivo aggregation of beta-amyloid peptide variants. J Neurochem 1998, 71:1616-1625.

20. Link CD, Fonte V, Roberts CM, Hiester B, Silverman MA, Stein GH: The beta amyloid peptide can act as a modular aggregation domain. Neurobiol Dis 2008, 32:420-425.

21. Link CD, Johnson CJ, Fonte $V$, Paupard M, Hall DH, Styren S, Mathis CA, Klunk WE: Visualization of fibrillar amyloid deposits in living, transgenic Caenorhabditis elegans animals using the sensitive amyloid dye, X-34. Neurobiol Aging 2001, 22:217-226.

22. Gong $Y$, Chang L, Viola KL, Lacor PN, Lambert MP, Finch CE, Krafft GA, Klein WL: Alzheimer's disease-affected brain: presence of oligomeric Abeta ligands (ADDLs) suggests a molecular basis for reversible memory loss. Proc Natl Acad Sci USA 2003, 100:10417-10422.

23. Barghorn S, Nimmrich V, Striebinger A, Krantz C, Keller P, Janson B, Bahr M, Schmidt M, Bitner RS, Harlan J, Barlow E, Ebert U, Hillen H: Globular amyloid beta-peptide oligomer - a homogenous and stable neuropathological protein in Alzheimer's disease. J Neurochem 2005, 95:834-847.

24. Lambert MP, Viola KL, Chromy BA, Chang L, Morgan TE, Yu J, Venton DL, Krafft GA, Finch CE, Klein WL: Vaccination with soluble Abeta oligomers generates toxicity-neutralizing antibodies. J Neurochem 2001, 79:595-605.

25. Lacor PN, Buniel MC, Chang L, Fernandez SJ, Gong Y, Viola KL, Lambert MP, Velasco PT, Bigio EH, Finch CE, Krafft GA, Klein WL: Synaptic targeting by Alzheimer's-related amyloid beta oligomers. J Neurosci 2004, 24:10191-10200.

26. Lacor PN, Buniel MC, Furlow PW, Clemente AS, Velasco PT, Wood M, Viola KL, Klein WL: Abeta oligomer-induced aberrations in synapse composition, shape, and density provide a molecular basis for loss of connectivity in Alzheimer's disease. J Neurosci 2007, 27:796-807.

27. De Felice FG, Wu D, Lambert MP, Fernandez SJ, Velasco PT, Lacor PN, Bigio EH, Jerecic J, Acton PJ, Shughrue PJ, Chen-Dodson E, Kinney GG, Klein WL: Alzheimer's disease-type neuronal tau hyperphosphorylation induced by A beta oligomers. Neurobiol Aging 2008, 29:1334-1347.

28. Magrane J, Smith RC, Walsh K, Querfurth HW: Heat shock protein 70 participates in the neuroprotective response to intracellularly expressed beta-amyloid in neurons. J Neurosci 2004, 24:1700-1706.

29. Magrane J, Rosen KM, Smith RC, Walsh K, Gouras GK, Querfurth HW: Intraneuronal beta-amyloid expression downregulates the Akt survival pathway and blunts the stress response. J Neurosci 2005, 25:10960-10969.

30. El Amri C, Lacombe C, Zimmerman K, Ladram A, Amiche M, Nicolas P, Bruston F: The plasticins: membrane adsorption, lipid disorders, and biological activity. Biochemistry 2006, 45:14285-14297.

31. Bruston F, Lacombe C, Zimmermann K, Piesse C, Nicolas P, El Amri C: Structural malleability of plasticins: preorganized conformations in solution and relevance for antimicrobial activity. Biopolymers 2007, 86:42-56.

32. Zangger K, Gossler R, Khatai L, Lohner K, Jilek A: Structures of the glycinerich diastereomeric peptides bombinin $\mathrm{H} 2$ and $\mathrm{H} 4$. Toxicon 2008, 52:246-254.

33. Soscia SJ, Kirby JE, Washicosky KJ, Tucker SM, Ingelsson M, Hyman B, Burton MA, Goldstein LE, Duong S, Tanzi RE, Moir RD: The Alzheimer's disease-associated amyloid beta-protein is an antimicrobial peptide. PLoS One 2010, 5:e9505.

34. Mueller M, Grauschopf U, Maier T, Glockshuber R, Ban N: The structure of a cytolytic alpha-helical toxin pore reveals its assembly mechanism. Nature 2009, 459:726-730.

35. Atkins A, Wyborn NR, Wallace AJ, Stillman TJ, Black LK, Fielding AB, Hisakado M, Artymiuk PJ, Green J: Structure-function relationships of a novel bacterial toxin, hemolysin E. The role of alpha G. J Biol Chem 2000, 275:41150-41155.

36. Harper JD, Lansbury PT Jr: Models of amyloid seeding in Alzheimer's disease and scrapie: mechanistic truths and physiological consequences of the time-dependent solubility of amyloid proteins. Annu Rev Biochem 1997, 66:385-407. 
37. Abedini A, Raleigh DP: A critical assessment of the role of helical intermediates in amyloid formation by natively unfolded proteins and polypeptides. Protein Eng Des Sel 2009, 22:453-459.

38. Kirkitadze MD, Condron MM, Teplow DB: Identification and characterization of key kinetic intermediates in amyloid beta-protein fibrillogenesis. J Mol Biol 2001, 312:1103-1119.

39. Hepler RW, Grimm KM, Nahas DD, Breese R, Dodson EC, Acton P, Keller PM, Yeager M, Wang H, Shughrue P, Kinney G, Joyce JG: Solution State Characterization of Amyloid beta-Derived Diffusible Ligands. Biochemistry 2006, 45:15157-15167.

40. Eckert A, Keil U, Marques CA, Bonert A, Frey C, Schussel K, Muller WE: Mitochondrial dysfunction, apoptotic cell death, and Alzheimer's disease. Biochem Pharmacol 2003, 66:1627-1634.

41. Chen X, Stern D, Yan SD: Mitochondrial dysfunction and Alzheimer's disease. Curr Alzheimer Res 2006, 3:515-520.

42. Atamna H, Frey WH: Mechanisms of mitochondrial dysfunction and energy deficiency in Alzheimer's disease. Mitochondrion 2007, 7:297-310.

43. Gidalevitz T, Ben-Zvi A, Ho KH, Brignull HR, Morimoto RI: Progressive disruption of cellular protein folding in models of polyglutamine diseases. Science 2006, 311:1471-1474.

44. Gidalevitz T, Krupinski T, Garcia S, Morimoto Rl: Destabilizing protein polymorphisms in the genetic background direct phenotypic expression of mutant SOD1 toxicity. PLoS Genet 2009, 5:e1000399.

45. Morley JF, Brignull HR, Weyers JJ, Morimoto RI: The threshold for polyglutamine-expansion protein aggregation and cellular toxicity is dynamic and influenced by aging in Caenorhabditis elegans. Proc Natl Acad Sci USA 2002, 99:10417-10422.

46. Yin H, Litvinov Rl, Vilaire G, Zhu H, Li W, Caputo GA, Moore DT, Lear JD, Weisel JW, Degrado WF, Bennett JS: Activation of platelet allb $\beta 3$ by an exogenous peptide corresponding to the transmembrane domain of allb. J Biol Chem 2006, 281:36732-36741.

47. Caputo GA, Litvinov Rl, Li W, Bennett JS, Degrado WF, Yin H: Computationally designed peptide inhibitors of protein-protein interactions in membranes. Biochemistry 2008, 47:8600-8606.

48. Dostal V, Roberts CM, Link CD: Genetic mechanisms of coffee extract protection in a Caenorhabditis elegans model of $\beta$-amyloid peptide toxicity. Genetics 186:857-866.

49. Dostal V, Link CD: Assaying beta-amyloid toxicity using a transgenic $C$. elegans model. J Vis Exp 2010, , 44: 2252.

50. Fonte V, Kipp DR, Yerg J, Merin D, Forrestal M, Wagner E, Roberts CM, Link CD: Suppression of in vivo beta-amyloid peptide toxicity by overexpression of the HSP-16.2 small chaperone protein. J Biol Chem 2008, 283:784-791

51. Florez-McClure ML, Hohsfield LA, Fonte G, Bealor MT, Link CD: Decreased insulin-receptor signaling promotes the autophagic degradation of betaamyloid peptide in C. elegans. Autophagy 2007, 3:569-580.

52. Decker H, Lo KY, Unger SM, Ferreira ST, Silverman MA: Amyloid-beta peptide oligomers disrupt axonal transport through an NMDA receptordependent mechanism that is mediated by glycogen synthase kinase 3 beta in primary cultured hippocampal neurons. $J$ Neurosci 30:9166-9171.

53. Lambert MP, Velasco PT, Chang L, Viola KL, Fernandez S, Lacor PN, Khuon D, Gong Y, Bigio EH, Shaw P, De Felice FG, Krafft GA, Klein WL: Monoclonal antibodies that target pathological assemblies of Abeta. I Neurochem 2007, 100:23-35.

54. Renner M, Lacor PN, Velasco PT, Xu J, Contractor A, Klein WL, Triller A: Deleterious effects of amyloid beta oligomers acting as an extracellular scaffold for mGluR5. Neuron 66:739-754.

doi:10.1186/1750-1326-6-61

Cite this article as: Fonte et al:: A glycine zipper motif mediates the formation of toxic $\beta$-amyloid oligomers in vitro and in vivo. Molecular Neurodegeneration 2011 6:61.

\section{Submit your next manuscript to BioMed Central and take full advantage of:}

- Convenient online submission

- Thorough peer review

- No space constraints or color figure charges

- Immediate publication on acceptance

- Inclusion in PubMed, CAS, Scopus and Google Scholar

- Research which is freely available for redistribution

Submit your manuscript at www.biomedcentral.com/submit
Biomed Central 